\title{
The Ortholog of LYVE-1 Is Required for Thoracic Duct Formation in Zebrafish ${ }^{*}$
}

\author{
Wen-Han Chen ${ }^{1 \#}$, Wen-Fang Tseng ${ }^{2 \#}$, Gen-Hwa Lin ${ }^{3 \#}$, Andrew Schreiner ${ }^{1}$, Hsiao-Rong Chen ${ }^{4}$, \\ Mark M. Voigt ${ }^{5}$, Chiou-Hwa Yuh ${ }^{2}$, Jen-Leih Wu ${ }^{3}$, Shuan Shian Huang ${ }^{6}$, Jung San Huang ${ }^{1 \dagger}$ \\ ${ }^{1}$ Department of Biochemistry and Molecular Biology, Saint Louis University School of Medicine, \\ Doisy Research Center, St. Louis, USA \\ ${ }^{2}$ Division of Molecular and Genomic Medicine, National Health Research Institutes, Chunan, Taiwan \\ ${ }^{3}$ Institute of Cellular and Organismic Biology, Academia Sinica, Taipei, Taiwan \\ ${ }^{4}$ Institute of Systems Biology and Bioinformatics, National Central University, Jhongli, Taiwan \\ ${ }^{5}$ Department of Pharmacology and Physiological Science, Saint Louis University \\ School of Medicine, St. Louis, USA \\ ${ }^{6}$ Auxagen Inc., St. Louis, USA \\ Email: †huangjs@slu.edu
}

Received August 22, 2013; revised September 22, 2013; accepted September 29, 2013

Copyright (c) 2013 Wen-Han Chen et al. This is an open access article distributed under the Creative Commons Attribution License, which permits unrestricted use, distribution, and reproduction in any medium, provided the original work is properly cited.

\begin{abstract}
LYVE-1 (also termed CRSBP-1), a 120-kDa disulfide-linked dimeric type I membrane glycoprotein, is a specific marker for lymphatic endothelial cells (LECs) and exhibits multiple ligand (hyaluronic acid and growth factors/cytokines) binding activity in mammals. Recent studies indicate that LYVE-1/CRSBP-1 ligands (VEGF-A ${ }^{165}$, PDGF-BB, oligopeptides containing the cell-surface retention sequence (CRS) motifs of VEGF-A ${ }^{165}$ and PDGF-BB) induce opening of lymphatic intercellular junctions in vitro and in vivo. To determine the function of the ortholog of mammalian LYVE-1 in zebrafish, we cloned it (zLyve-1). The cloned cDNA (zlyve1) encodes a 328-amino-acid type I membrane glycoprotein. The protein and genomic structure evidence supports the notion that the cloned zLyve- 1 is the ortholog of LYVE-1 in zebrafish. zLyve-1 expressed in cultured cells by transfection exhibits hyaluronic acid binding activity but lacks the growth factor binding activity seen in mammalian homologs. Knockdown of zLyve-1 levels by embryo microinjection with a specific antisense morpholino oligonucleotide (MO2) in wild-type and $T g(f l i 1: E G F P)$-transgenic zebrafish causes defects in thoracic duct (TD) formation. Such zebrafish injected with MO2 also exhibit impaired TD flow (as determined by intramuscular injection of FITC-dextran). The phenotypes in these zebrafish injected with MO2 are reversed by co-injection with zlyve1cDNA. In situ hybridization reveals that zLyve-1 is expressed in the posterior cardinal vein (PCV). Expression of zLyve-1 at the highest level in the PCV occurs at 3 dpf which coincides with the time for TD formation in zebrafish development. These results suggest that zLyve-1 is required for TD formation. They also suggest that zLyve-1 is distinct from mammalian LYVE-1 in its role in lymphatic function.
\end{abstract}

Keywords: zLyve-1; Morpholino Knockdown; Thoracic Duct; Posterior Cardinal Vein Endothelial Cells

\section{Introduction}

Cell-surface retention sequence (CRS)-binding protein-1 (CRSBP-1) was identified in cultured transformed cells

\footnotetext{
*Conflict of Interest: Jung San Huang and Shuan Shian Huang had equity positions in Auxagen, Inc. when the research was performed. Part of the research was supported by NIH grants awarded to Auxagen, Inc. (AR052578).

This work was presented at the Meeting "Lymphatic Circulation in Health and Disease”, May 3-4, 2013, New Haven, CT, USA.

"Contributed equally

${ }^{\dagger}$ Corresponding author.
}

and plasma membranes purified from liver tissue in 1995 by its ability to bind PDGF-BB, VEGF-A ${ }^{165}$ and synthetic oligopeptides containing the CRS motifs of PDGF-BB and VEGF-A $\mathrm{A}^{165}[1,2]$. The CRS motifs contain a cluster of basic amino acid residues (Arg, Lys, His). cDNA cloning, sequencing and expression of bovine CRSBP-1 in 2003 [3] revealed that CRSBP-1 is identical to lymphatic vessel endothelial hyaluronic acid (HA) receptor-1 (LYVE-1), which was identified by CD44 homology cloning in 1999 [4]. LYVE-1 has been used as a specific marker for lym- 
phatic endothelial cells (LECs) and lymphatic vessels in mammals [5]. CRSBP-1/LYVE-1 expressed in cultured cells is a $120-\mathrm{kDa}$ disulfide-linked dimeric type I membrane glycoprotein, and exhibits multiple ligand (hyaluronic acid and growth factors/cytokines) binding activity in mammals [3]. Recent studies indicate that CRSBP1/LYVE-1 ligands (such as hyaluronic acid, PDGF-BB, VEGF-A ${ }^{165}$ and synthetic oligopeptides containing the CRS motifs of VEGF-A ${ }^{165}$ and PDGF-BB) induce opening of lymphatic intercellular junctions in vitro and in vivo, resulting in an increase in the transit of fluid, large molecules and cells from the interstitial space into lymphatic vessel lumens (termed interstitial-lymphatic transit) in mice [6-8].

We hypothesized that CRSBP-1/LYVE-1 plays an import role in lymphatic function in all vertebrate animals, including zebrafish. To test this hypothesis, our studies aimed at cloning the zebrafish ortholog (zLyve-1) of mammalian LYVE-1 and defining its role in lymphatic vessel formation and function. The lymphatic vasculature has been characterized in zebrafish [9-12]. Zebrafish possess a lymphatic vascular system that has morphological, molecular and functional characteristics like those found in other vertebrates [9-12]. It is an excellent animal system in which to investigate how lymphatic vessel formation and function are determined by proteins specifically expressed in LECs. Gene expression knockdown by embryo microinjection with specific antisense morpholino oligonucleotides (MOs) is a simple and effective strategy to define the roles of target genes in the development of lymphatic vessels in zebrafish in a relatively short time (days) $[13,14]$. Compared to other vertebrates, the zebrafish offers several other advantages including small size, optical clarity (fluorescent blood and lymphatic vessel structures are easy to see in transgenic Tg(fli1:EGFP) zebrafish) and rapid development (days) of embryos [15].

In this communication, we show the cloning of zlyve1 cDNA from zebrafish RNA at the 2 - 5 dpf stages by RT-PCR. The analyses of genomic and putative protein structures of the identified zLyve-1 suggest that zLyve-1 is the ortholog of mammalian LYVE-1 in zebrafish. We also show that zLyve-1 expressed in cultured cells exhibits hyaluronic acid-binding activity but lacks the growth factor-binding activity seen in mammalian LYVE-1, as determined by cetylpyridinium chloride precipitation and ${ }^{125}$ I-labeled VEGF (vascular endothelial cell growth factor) peptide-affinity labeling [3], respectively. This is consistent with the presence of Link module and absence of the putative growth factor binding domain (the acidicamino-acid-rich region) in zLyve-1 molecule. In addition, we show that zebrafish derived from both wild-type and fluorescent transgenic $\mathrm{Tg}($ fli1:EGFP) embryos microinjected with a specific antisense morpholino oligonucleo- tide (MO2) exhibit defects in thoracic duct formation and impaired thoracic duct flow (as determined by intramuscular injection of FITC-dextran). These phenotypes can be reversed by co-injection with zlyve1 cDNA. Furthermore, we show that zLyve-1 is expressed in the posterior cardinal vein (PCV), as evidenced by in situ hybridization. Since PCV endothelial cells are known to be precursor cells for LECs forming the thoracic duct (TD), this suggests that zLyve-1 expressed in PCV endothelial cells may play an important role in lymphatic development in zebrafish.

\section{Materials and Methods}

\subsection{Materials}

$\mathrm{Na}^{125} \mathrm{I}$ (100 mCi/mL), was purchased from MP Biochemicals (Solon, OH). VEGF peptide (a 25-mer peptide containing the amino acid sequence KKSVRGKGKGQKRKRKKSRYKSWSV) was synthesized by C S Bio Co. (Menlo Park, CA). Cetylpyridinium chloride (CPC), 1ethyl-3-(3-dimethylaminopropyl) carbodiimide $\mathrm{HCl}$ (EDAC), Triton X-100, hyaluronic acid (M.W. 2,000,000) from human umbilical cord ( 98\% purity), chloramine $\mathrm{T}$ and FITC-dextran were obtained from Sigma (St. Louis, MO). Anti-hemagglutinin (HA) epitope antibody was obtained from Cell Signaling (Danvers, MA). pCMV-HA was obtained from Clontech (Mountain View, CA). H1299/bLYVE-1 and H1299/vector cells, which were stably transfected with pCEP-bLYVE-1 cDNA and pCEP vector only, respectively, were prepared as previously described [3]. H1299 cells (human lung carcinoma cells) were transiently transfected with zlyve1 cDNA in the pCMV-HA vector (pCMV-zlyve1-HA) and termed H1299/zlyve1 cells which expressed HA-tagged zLyve-1.

\section{2. zlyve1 and zlyve1l cDNA Construction}

zlyve 1 cDNA was amplified from zebrafish RNA at the 2 - 5 dpf stages by RT-PCR using the high capacity RNA-to-cDNA Kit ${ }^{\text {TM }}$ (Applied Biosystems, Foster City, CA), and KOD FX DNA polymerase (Toyobo Biochemicals, Osaka, Japan). The primer sequences used for PCR were 5'-ATGACACGAGTCTGCATGGG-3' (forward), and

5’-TCATTGTTCTGCAGAGCTACTGTCG-3' (reverse). The amplified cDNA was inserted into the yT \& A vector (Yeastern, Taipei, Taiwan) via T-A cloning. The KpnI and XbaI fragment was then sub-cloned into pCMV-HA at KpnI and NotI fill-in sites and termed pCMV-zlyve1-HA. The cDNA (zlyve1l) of zebrafish Lyve-1-like protein was also cloned from zebrafish RNA at the 2 - 5 dpf stages using RT-PCR in a similar manner. The CMV promoter is a universal promoter and functional in the zebrafish system. 


\subsection{Multiple Alignments, Phylogenetic Analysis and Genomic Structural Analysis of zlyve1 (zLyve-1), zlyve1l (zLyve-1-Like) and Other LYVE-1 Vertebrate Homologs}

After cDNA cloning of zLyve-1 and zlyve1-like protein, multiple alignments of these cDNAs with those of other vertebrate orthologs (human, chimpanzee, dog, cow, mouse, rat, chicken and salmon) were performed using the NCBI multiple alignment program. In addition to the multiple alignments, a phylogenetic tree was created using the results from the multiple alignment section of the same program. Genomic structure analysis was also performed using the NCBI sequence viewer for zlyve1, zlyve1l and other vertebrate orthologs.

\subsection{Transfection}

H1299 cells were transiently transfected with pCMVzlyve1-HA and pCMV-HA, using lipofectamine as described [3] and termed H1299/zlyve1 and H1299/vector cells, respectively.

\subsection{Hyaluronic Acid Binding Activity Assay}

The $0.1 \%$ Triton $\mathrm{X}-100$ extracts (100 $\mu$ g protein) of H1299 cells transiently transfected with pCMV-zlyve1HA (H1299/zlyve1 cells) were incubated with several concentrations of hyaluronic acid (average M.W. 2,000,000) at room temperature for $1 \mathrm{~h}$. The reaction mixtures were then subjected to CPC precipitation and analyzed by 7.5\% SDS-PAGE, followed by Western blot analysis using anti-HA antibody (to immunoprecipitate HAtagged zLyve-1 expressed in H1299/zlyve1 cells). The antigens on the blots were visualized using horseradish peroxidase-conjugated anti-rabbit IgG antibody and the ECL system, as described [3]. The relative intensities of antigen (HA-tagged zLyve-1 which formed complexes with hyaluronic acid) bands on X-ray films were quantified by densitometry.

\section{6. ${ }^{125}$ I-VEGF Peptide Binding Assay}

${ }^{125}$ I-VEGF peptide was prepared using $\mathrm{Na}^{125} \mathrm{I}$ and chloramine $\mathrm{T}$ as described [1-3,7]. The ${ }^{125}$ I-VEGF peptide binding assay in cultured cells was carried out according to our published procedure [1,3]. Briefly, H1299/ vector, H1299/bovine LYVE-1 (H1299/bLYVE-1) [3] and H1299/zlyve1 cells seeded at the same cell density were incubated with $6 \mu \mathrm{M}{ }^{125}$ I-VEGF peptide with and without 100-fold excess of unlabeled VEGF peptide. After $2.5 \mathrm{~h}$ at $4^{\circ} \mathrm{C}$, the specific binding of ${ }^{125} \mathrm{I}$-VEGF peptide was estimated by subtracting nonspecific binding, which was determined in the presence of 100 -fold excess of unlabeled VEGF peptide, from total binding.

\section{7. ${ }^{125}$ I-VEGF Peptide-Affinity Labeling}

The ${ }^{125}$ I-VEGF peptide-affinity labeling in cultured cells was carried out as described [1-3,7]. H1299/vector, H1299/bLYVE-1, and H1299/zlyve1 cells were incubated with $6 \mu \mathrm{M}{ }^{125}$ I-VEGF peptide with and without 100 -fold excess of unlabeled VEGF peptide. After $2.5 \mathrm{~h}$ at $4^{\circ} \mathrm{C},{ }^{125}$ I-VEGF peptide-affinity labeling was carried out by adding EDAC into cells and incubating at $4^{\circ} \mathrm{C}$ for an additional 15 min. ${ }^{125}$ I-VEGF peptide-affinity labeled cells were subjected to Triton X-100 lysis followed by 7.5\% SDS-PAGE and autoradiography.

\subsection{Husbandry and Maintenance of Zebrafish}

We performed zebrafish (Danio rerio) studies according to the US National Institute of Child Health and Human Development Animal Care and Use Committee guidelines for the use of laboratory animals (St. Louis University IACUC office) and those of Academia Sinica, Taiwan, and National Health Research Institutes, Taiwan. Wild-type zebrafish (AB strain) were obtained from natural crosses and subsequent collection of embryos. Embryos were collected by natural spawning, raised in $0.3 \times$ Danieau's buffer and then maintained in fish water at $28.5^{\circ} \mathrm{C}$, with feeding twice daily until experiments. The wild-type zebrafish and fluorescent transgenic $T g$ (fli1: EGFP) zebrafish were also maintained at the facilities (St. Louis University School of Medicine and the Institute of Cellular and Organismic Biology, Academia Sinica, Taipei, Taiwan and Division of Molecular and Genomic Medicine, National Health Research Institutes, Chunan, Taiwan) in a controlled environment with a $14 / 10$-h light-dark cycle at $28^{\circ} \mathrm{C}$. The fish spawned soon after light onset, and fertilized eggs were collected at the 1-cell stage. The embryos were collected using naturalmating and cultured at $28^{\circ} \mathrm{C}$ in Ringer's solution.

\subsection{Antisense Morpholino Oligonucleotide (MO) Microinjection}

MO1, MO2, MO3, mis-paired MO2, mis-paired MO3 and control MO were obtained from Gene Tools, LLC (Philomath, OR). Six MOs (MO1, MO2, mis-paired MO2, MO3, mis-paired MO3 and control MO) included: splice site blockers that targeted the 5'UTR (MO1: 5'-TCATCCCCATGCAGACTCGTGTCAT-3'); the boundary between exon1 and intron 1 (MO2: 5'-TCGAGGCAGATCTTACCTTTACAA-3'; mis-paired MO2: 5'-TCGAGcCAcATCTTAgCTTTAAgAA), and the boundary between intron 1 and exon 2 (MO3: 5'-TGCACTGTTCATCAGAAGAAAGCAG-3'; mis-paired MO3: 5'-TGCAgTcTTCATCACAAcAAAcCAG-3'), and a control MO (5'TCGAGCCACATCTTAGCTTTAAGAA-3') (MO). MOs were dissolved in doubly distilled $\mathrm{H}_{2} \mathrm{O}$ to make a stock 
solution with a concentration of $\sim 8.4 \mathrm{ng} / \mathrm{nl}$ or $1 \mathrm{mM}$, stored at RT and further diluted to the working concentration $(0.1 \mathrm{mM})$ with $0.1 \%$ phenol red or diluted with $2 \times$ phenol red dye $(0.1 \mathrm{M} \mathrm{KCl,} 20 \mathrm{mM}$ HEPES, pH 7.4 and $0.01 \%$ phenol red) at a $1: 4$ dilution for injection. Final concentrations of MOs were $\sim 2 \mathrm{ng} / \mathrm{hl}$ or $0.25 \mathrm{mM}$. A volume of 1 and $2 \mathrm{nl}$ of MOs (4.2 and $8.4 \mathrm{ng}$ per embryo), which was backloaded into microinjection needles, was injected into 1-cell stage embryos using a Picospritzer III (General Valve Corporation, Fairfield, NJ) attached to a broken capillary tube. For rescue experiments, $100 \mathrm{pg}$ of zlyve1 cDNA, which was purified using Qiaquick spin columns (Qiagen), or pCMV-HA vector was co-injected with MO2 or control MO into zebrafish embryos.

\subsection{RT-PCR Analysis}

Total RNAs from 5 embryos at designated stages were isolated by the use of RNA STAT- $60^{\mathrm{TM}}$ reagent (Tel-Test, Inc, USA) or TRIZOL reagent (Invitrogen). First-strand cDNA was synthesized in a $20 \mu \mathrm{l}$ R reaction from $1 \mu \mathrm{g}$ of total RNA by using Super Script III First-Strand synthesis system (Invitrogen), according to the manufacturer's instructions. zlyve1 cDNA fragments of 308 bp and 461 bp were amplified with the following two-pair primers: 5'-G GCCTGTTCATGTCTGGTCTG-3' (forward)/5'-TCTGCACGCCACACCACAACC-3' (reverse) and 5'-ATG ACA CGA GTC TGC ATG GG-3' (forward)/5'-ATC GGC TTT CCG GTT GTC ATT TGG-3' (reverse), respectively. Amplification was carried out in a thermal cycler (2720 thermal cycler, Applied Biosystems, USA) by $30 \mathrm{~s}$ denaturation at $94^{\circ} \mathrm{C}, 30 \mathrm{~s}$ annealing at $55^{\circ} \mathrm{C}$ and $30 \mathrm{~s}$ extension at $72^{\circ} \mathrm{C}$. A total of 35 cycles were carried out. The $\beta$-actin and $18 \mathrm{~s}$ rRNA RT-PCR products (433 and 241 base pairs, respectively) in total RNAs isolated were used as internal controls.

\subsection{FITC-Dextran Microinjection}

Using a conventional microinjection setup, 5 - 7 dpf embryos were embedded in $2 \%$ low-melting point agarose, and $2.5 \mathrm{ng} / \mathrm{nl}$ FITC-dextran (average M.W. 2,000,000) was injected into the tail muscles of zebrafish embryos. Embryos were then imaged every 2 - 3 minutes for evaluation of movement of the large fluorescent molecule. The rate (segments/min) of FITC-dextran fluorescence transit along the thoracic duct was measured between 5 and 20 min after injection of FITC-dextran. The FITC-dextran transit time from injection site to the visible end of the thoracic duct was approximately $20 \mathrm{~min}$.

\subsection{Whole-Mount in Situ Hybridization}

A cDNA fragment of zlyve1 or zlyve1l was cloned into a cloning vector as the DNA template for synthesizing an antisense RNA probe. The T3 polymerase promoter sequence was added to the 3' end of the cDNA by insertion into the 5' end of the reverse primer. Digoxigenin (DIG)labeled antisense RNA probes were synthesized from the purified PCR products according to the instructions in the MEGAscript Kit (Ambion, Austin, TX) and DIG RNA labeling mix (Roche). Zebrafish larvae at $30 \mathrm{hpf}, 3$ dpf, $4 \mathrm{dpf}$ and $5 \mathrm{dpf}$ were fixed with $4 \%$ paraformaldehyde overnight at $4^{\circ} \mathrm{C}$ and dehydrated in methanol at $-20^{\circ} \mathrm{C}$. Whole mount in situ hybridization was performed according to the protocol described by the Thisse Lab (https://wiki.zfin.org/display/prot/Thisse+Lab+-+In+Situ +Hybridization+Protocol+-+2010+update) with some modifications. Briefly, zebrafish embryos were rehydrated gradually with PBST (1× PBS, $0.1 \%$ Tween 20) and treated with proteinase $\mathrm{K}$ for $30 \mathrm{~min}$. After being prehybridized with $\mathrm{HYB}^{-}$(50\% formamide, $5 \times \mathrm{SSC}$, and $0.1 \%$ Tween 20), zebrafish were incubated at $65^{\circ} \mathrm{C}$ overnight in $\mathrm{HYB}^{+}\left(\mathrm{HYB}^{-}\right.$plus $50 \mu \mathrm{g} / \mathrm{ml}$ heparin, $500 \mu \mathrm{g} / \mathrm{ml}$ wheat germ tRNA) containing $1 \mu \mathrm{g} / \mu \mathrm{l}$ of the DIG-labeled antisense RNA probe. They were then washed with $75 \%, 50 \%$ and $25 \% \mathrm{HYB}^{-} / 2 \times$ SSC for $15 \mathrm{~min}, 2 \times \mathrm{SSC}$ for $15 \mathrm{~min}$, and twice with $0.2 \times \mathrm{SSC}$ for $30 \mathrm{~min}$ at $70^{\circ} \mathrm{C}$ and transferred gradually to maleic acid buffer (100 mM maleic acid, $150 \mathrm{mM} \mathrm{NaCl,} 0.1 \%$ Tween 20) and blocked in $1 \times$ blocking buffer [1\% Blocking Reagent (Roche) in maleic acid buffer] for at least $2 \mathrm{~h}$. Zebrafish were then incubated in 1:5000 anti-DIG-AP (Roche) in $1 \times$ blocking buffer overnight at $4^{\circ} \mathrm{C}$. After six washes with PBST for $15 \mathrm{~min}$ and three washes with alkaline Tris buffer for $5 \mathrm{~min}$, bound antibody was detected using BCIP/NBT (Roche). After staining, the labeled larvae were mounted in $2 \%$ methylcellulose. The images were captured using ZEISS ImagerA1 and ZEISS AxioImagerA1 and processed with their associated software.

\subsection{Statistical Analysis}

The values are presented as mean \pm S.D. Two-tailed unpaired Student's $t$-test was used to determine the significance of differences between groups. $P<0.05$ was considered significant. Comparisons between the two groups were conducted with the Mann-Whitney test.

\section{Results}

\subsection{Cloning of zlyve1 cDNA}

Before cloning the zlyve1 cDNA, we performed a homology search in the zebrafish gene bank using mammalian LYVE-1. We found two genes; one of which was recently identified by Flores et al. [16] and one other, which we named zLyve-1. Because of the protein structure homology found among mammalian LYVE-1, including salmon LYVE-1 (sLYVE-1) and zebrafish Lyve- 
1 (zLyve-1), we believe that zLyve-1 is the ortholog of mammalian LYVE-1 in zebrafish. We therefore cloned zlyve1 cDNA using the primers generated based on the putative zlyve 1 cDNA sequence. The cDNA (zlyve1) of the zebrafish LYVE-1 ortholog (zLyve-1) was cloned from zebrafish RNA at 2 - 5 days post fertilization (dpf) using RT-PCR. We obtained the cDNA nucleotide sequence of the cloned zlyve1 (Figure 1(A)). The zlyve1 cDNA encodes a 328-amino-acid type I membrane glycoprotein containing a 10 -amino-acid putative signal peptide, a 187-amino-acid cell-surface domain which includes a 77-amino-acid Link module [17], a 23-aminoacid transmembrane domain and a 93-amino-acid cyto- plasmic domain (Figure 1(B)). Comparison of the nucleotide and deduced amino acid sequences of zLyve-1 with those of other vertebrate homologs revealed that zLyve-1 has 22\% - 45\% amino acid and nucleotide sequence identity with those of the salmon, chicken, rat, mouse, cow, dog, chimpanzee and human homologs (Figure 1(B)). zLyve-1 and other known vertebrate LYVE-1 homologs share important protein structural features (Figure 1(C), panels a, b and c). It is important to note that all vertebrate homologs, including zLyve-1 and sLYVE-1, possess two N-glycosylation sites on both sides of the Link module (Figures 1(B) and (C), panels a, b and c). A zebrafish LYVE-1 ortholog, which was re-

\section{ATGACACGAGTCTGCATGGGGATGATGATGATGATGATTAAGATGGTGCTTTTCAGTGGC \\ $\begin{array}{lllllllllllllllllllll}M & T & R & V & C & M & G & M & M & M & M & M & I & K & M & V & L & F & S & G & 20\end{array}$ \\ CTGTTCATGTCTGGTCTGGCGTTTGACATGCAGCTTGTAAAAGTGCACCCTAAACAAGCC \\ $\begin{array}{lllllllllllllllllllll}\text { L } & F & M & S & G & \text { L } & A & F & D & M & Q & L & V & K & \text { V } & \text { H } & \text { P } & \text { K } & \text { Q } & \text { A } & 40\end{array}$ \\ ATCTCCGGGGTATCAGAAGCTTCCATTGGGAATCAATATGCTTTAAACGCATCATCAGCC \\ \begin{tabular}{llllllllllllllll|lllllll} 
I & $S$ & $G$ & $V$ & $S$ & $E$ & $A$ & $S$ & $I$ & $G$ & $N$ & $Q$ & $Y$ & $A$ & $L$ & $N$ & $A$ & $S$ & $S$ & $A$ & 60
\end{tabular} \\ AGAGATCTTTGTGAGCATCTCGGATTGACGATTGCAAACAAAGCACAGCTAGCAGAGGCT \\ $\begin{array}{lllllllllllllllllllll}R & D & L & \text { (C) } & E & H & \text { L } & G & \text { L } & \text { T } & \text { I } & \text { A } & N & \text { K } & \text { A } & \text { Q } & \text { L } & \text { A } & \text { E } & \text { A } & 80\end{array}$ \\ CAGAAACACGGCCTGGAGACGTGCAGGTTCGGGTGGATCGATGAGCAGATCGCTGTTGTT \\ $\begin{array}{lllllllllllllllllllll}\text { Q } & \text { K } & \text { H } & \text { G } & \text { L } & \text { E } & \text { T } & \text { (C) } & R & \text { F } & \text { G } & \text { W } & \text { I } & \text { D } & \text { E } & \text { Q } & \text { I } & \text { A } & \text { V } & \text { V } & 100\end{array}$ \\ CCTCGAGTCAAGGTTAACCCCAACTGCGGCAATGGCAAGACTGGGGTTGTGGTGTGGCGT \\ $\begin{array}{lllllllllllllllllllll}P & R & V & K & V & N & P & N & (C) & G & N & G & K & T & G & V & V & V & W & R & 120\end{array}$ \\ GCAGATCCCAGCAAACAATTTGATGTCTTTTGCTTCAATGTAACCGATTTTGAGACACAG

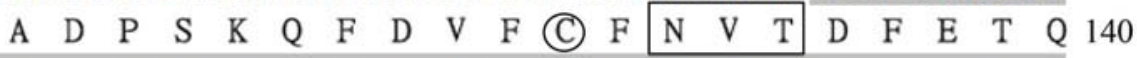 \\ GCTTCCATAAAGGTGCACCAAATGACAACCGGAAAGCCGATGACGACACGTTCATCTGTG \\ $\begin{array}{lllllllllllllllllllll}\text { A } & S & I & K & V & H & Q & M & T & T & G & K & P & M & T & T & R & S & S & V & 160\end{array}$ \\ GCTCCTACTGCTGGAGTTCATCTGAGGGGAAGCCCATTATCTAAACTCCCTTCCCATTGG \\ $\begin{array}{llllllllllllllllllllll}\text { A } & \text { P } & \text { T } & \text { A } & \text { G } & \text { V } & \text { H } & \text { L } & \text { R } & G & \text { S } & \text { P } & \text { L } & \text { S } & K & \text { L } & \text { P } & \text { S } & \text { H } & \text { W } & 180\end{array}$ \\ TCCAGTGTTCCTCGTTCAGCGTCTGCAGGTCCCTCTGTGGTCCACAGGGCTGATGCCAAA \\ $\begin{array}{llllllllllllllllllllll}S & S & V & P & R & S & A & S & A & G & P & S & V & V & H & R & A & D & A & K & 200\end{array}$ \\ CATCTTGCCCTGAGCAGTGGCTCCACTGAAGCTGTTCCTGCCGCTTTACTGATCACCGTC \\ $\begin{array}{lllllllllllllllllllll}\text { H } & \text { L } & \text { A } & \text { L } & \text { S } & \text { S } & G & \text { S } & \text { T } & \text { E } & \text { A } & \text { V } & \text { P } & \text { A } & \text { A } & \text { L } & \text { L } & \text { I } & \text { T } & \text { V } & 220\end{array}$ \\ ACCTTTGCAGTCATGATTGCTGTGTTTCTGGCACTTTATTATGTCAGAACGAAAAGACCC \\ $\begin{array}{lllllllllllllllllllll}T & F & A & V & M & I & A & V & F & \text { L } & A & \text { L } & Y & Y & V & R & T & K & R & P & 240\end{array}$ \\ TGCAAGGCCCAGTGTGATGTAGAGCAGCAGAAGGAGTACATCGAGACTGAGGTTTGGGAA \\ $\begin{array}{lllllllllllllllllllll}C & K & A & Q & C & D & V & E & Q & Q & K & E & Y & \text { I } & E & T & E & V & \text { W } & \text { E } & 260\end{array}$ \\ CACCATACTAAAGAAGACCTGCAGAAAACACAAGAGGAACAGGTGGAGGACAAAAACCAG \\ $\begin{array}{lllllllllllllllllllll}\text { H } & H & \text { T } & \text { K } & \text { E } & \text { D } & \text { L } & \text { Q } & \text { K } & \text { T } & \text { Q } & \text { E } & \text { E } & \text { Q } & \text { V } & \text { E } & \text { D } & \text { K } & \text { N } & \text { Q } & 280\end{array}$ \\ GAGGAGCAGATGGAGGAAAAGAACCAGGAAGAGCTGGATGAGAATCACCAGGAGGAGCAG

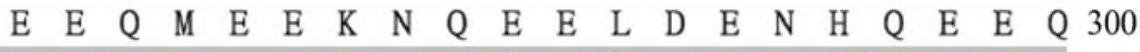 \\ ATGGAGGAGAGACGCCAAGAAGAGCACATGAAGAAAAACCAGGAGGAGCAGGTGGAGGAA \\ $\begin{array}{lllllllllllllllllllll}M & E & E & R & R & Q & E & E & H & M & K & K & N & Q & E & E & Q & V & E & E & 320\end{array}$ \\ AACGACAGTAGCTCTGCAGAACAATGA \\ $\begin{array}{llllllllllll}N & D & S & S & S & A & E & Q\end{array}$ \\ 328}


Human LYVE-1 1 chimpanzee LYVE-1 1 Dog LYVE-1 1 Cow LYVE-1 1

Mouse LYVE-1 1 Rat LYVE-1 1

Chicken LYVE-1 1

Salmon LYVE-1 1

Zebrafish Lyve-1 1
Human LYVE-1 chimpanzee LYVE-1 Dog LYVE-1 COW LYVE-1

Mouse LYVE-1 Rat LYVE-1

Chicken LYVE-1

Salmon LYVE-1

Zebrafish Lyve-1

Human LYVE-1 chimpanzee LYVE-1 Dog LYVE-1

CoW LYVE-1

Mouse LYVE-1

Rat LYVE-1 147

Chicken LYVE-1 145

Salmon LYVE-1 141

Zebrafish Lyve-1 156

Human LYVE-1 229 chimpanzee LYVE-1

Dog LYVE-1

COW LYVE-1 229

Mouse LYVE-1 225

Rat LYVE-1 221

Chicken LYVE-1 215

Salmon LYVE-1 192

Zebrafish Lyve-1 212
MARCFS--LVLLLTSIWTTRLLVOG-SL MARCFS--LVLLLTSIWTTRLLVQG-SLRAEELSIQVSCRIMGITLVSKKA------NQQLNFTEAKEACRLLGLSLAGKD MAKCFS--LVLLLASIWTTRLLVHA-TLRVEELSISGPCRIVGVTLVNKKT------IQQLNFTEAQEACRLMGLTLASKD MAKFFS--LGLLLASIWTTRLLVQG-SLRSEELSILGPCRIMGVTLVTKKT------QPLLNFTEAQEACRLVGLTLASQD MLQHTS--LVLLLASIWTTRHPVQG-ADLVQDLSIS-TCRIMGVALVGRNK------NPQMNFTEANEACKMLGLTLASRD MLQHCS--LVLLLASLWTTRHPVHG-TVQVQDLSIS-PCRIMGVALVGRNA------DPQMNFTEAKEVCKVLGLTLASRN MTTYFG--VTSAVLSVWVMTFMAQN-YFITG--STLSPCRITGVGLYL--------GHKVNFSEASNVCNRLNLQLASKE MMQVWI------LSLLLPLTLSFSGLHVDPSKIHAFPERHIAGVFLVSYTKDLNQFAYAFNASEAREVCWSLGVTMASNS MTRVCMGMMMMMIKMVLFSGLFMSGLAFDMQLVKVHPKQAISGVSEASIGN-----QYALNASSARDLCEHLGLTIANKA

QVETALKASFETCSYGWVGDGFVVISRISPNPKCGKNGVGVLIWKVPVSRQFAAYCYNSSDTWTNSCIP-EIITTKDPIF QVETALKASFETCSYGWVGDGFVVISRISPNPKCGKNGVGVLIWKVPVNRQFAAYCYNSSDTWTNSCIP-EIITTKDPIF QVEAARRSGFETCSYGWVADKLLVIPRILPNPKCGKNGIGVLVWRNSLSKKFLAYCYNSSDTWINSCIP-EIITTTDPIF QVEEARKFGFETCSYGWVKNQFVVIPRI ISNPKCGKSGVGVVIWRSSLSSRHRSYCHNSSDIWINSCLP-EIITTDDPLF QVESAQKSGFETCSYGWVGEQFSVIPRIFSNPRCGKNGKGVLIWNAPSSQKFKAYCHNSSDTWVNSCIP-EIVTTFYPVI QVESAQKSGFETCSYGWVGERFSVIPRISPNPKCGKNGKGVLIWNASPSQKFRVYCHNSSDTWANSCFP-EITTTF---QVEKALNHGFETCSSGWIKDGSVAIPRITSNMKCGKGSVGLVNWRPNHAHKFTVYCFNSSDVQINSCKP-DPTTTIIP-QVEEAQRLGLETCRFGWIDEHFAVIPRIEASKTCGQNQTGVIKWRASVTKLFDVFCFNASGV---ASFP--------QLAEAQKHGLETCRFGWIDEQIAVVPRVKVNPNCGNGKTGVVVWRADPSKQFDVFCFNVTDFETQASIKVHQMTTGKPMT $\Delta$
$\Delta$
NTQTATQTTEFIVSDSTYSVASPYSTIPAPTTTPPAP--ASTSIPRRKKLICVTEVFMETS-TMSTETEPFVENKAAFKN NTQTATHTTEFIVSDSTYSVASPYSTIPAPTTTPPAP--ASTSIPRRKKLICVTEVFMETS-TMSTETEPFVENKAAFKN NIQETIYTTEMIVSDSTYSASSTDAPYSATPTLAPTSALASTSTRRKRKLICVTEAFVETS-TVSTETESYIENKAAFKN NTETATYTTKLMVSDSTHSELSTDGPDYVTTTVAPP--LASTSTPRKRKLICITEAFMDTS-AVATERESDIQNRPAFKN DTQTP--ATEFSVSSSAYLASSPDSTTPVSATTRAPP---LTSMARKTKKICITEVYTEPI-TMATETEAFVASGAAFKN NTQTP--AAEFSVSSDTYSASSSDSTTSASATTRAPP---LTTMARKTKMICITEVYTEPI-TMDAETEASVESGAAFKN ---SSSVPTDLTAYSSS---DLTGNTTAVPTAAEPEQ----TLKNVKFRIICITETILPTEETTTTMPEESYTYPAAFRN -STSLS-PAI IHLVPSTQS-------------TRPTS-------HSRSSLLSLSSFSDNPE--------EVEVELPQSMSS TRSSVAPTAGVHLRGSPLS-KLPSHWSSVPRSASAGP---SVVHRADAKHLALSSGSTEA--

$\Delta$

EAAGFGGVPTALLVLALLFFGAAAGLGFCYV--KRYVKA-FPFTNKNQQKEMIET-KVVKEEKANDSNPNEESKKTDKNP EAAGFGGVPTALLVLALLFFGAAAGLGFCYV--KRYVKA-FPFTNKNQQKEMIET-IVVKEEKANDSNPNEELKKTDKNP EVVGFGGVPTALLVLALLFFAAAAGLAVCYV--KRYVKT-FPFTNKNQQKEMIET-KVVKEEKADDSNPNEESKKTDKKP EAVGFGGVPTALLVLALLFFAAAAGLAVCYV--KRYVKA-FPFTNKNQQKEMIET-KVVKEEKADDSNPNEESKKMNKTP EAAGFGGVPTALLVLALLFFGAAAVLAVCYV--KRYVKA-FPFTTKNQQKEMIET-KVVKEEKADDVNANES SKKTIKNP EAAGFGGVPTTLLVLALFFFGAAAVLGVCYV--KRYVKA-FPFTNKNQQKEMIET-KVVKEEKADDVNANEESKKMVKNS DGVVFGGIPTALLVLAIIFFISSVLLAVCYI--KKYKKC-LLF SRKNQKKEVVET-TALKDTASNDKILEKETKNNGKMV AKSSIGAVPKALLITSAIVLLLTAMAILLYFRANNGLKTIFPCWDLEQQKEYSETVECAAHTCMKDTKEVQTEGKAKAEP

\begin{tabular}{|c|c|c|}
\hline Human LYVE-1 & 305 & EE---SK------------SPSKTTVRCLE--------- \\
\hline impanzee LYVE-1 & 305 & EE---PK-----------SPSKTTVRCLE--- \\
\hline Dog LYVE-1 & 307 & EE---PK-------------SPTKTTVRCME--------------------AEV \\
\hline Cow LYVE-1 & 305 & --SPPKTTVRCLE--- \\
\hline Mouse LYVE-1 & 301 & ---SPPKTTVRCLE--- \\
\hline Rat LYVE-1 & 297 & EE---PK------------SPPKTTVRCLE---------------AEV \\
\hline Chicken LYVE-1 & 291 & EE---AT------------AKPETTVKCLE---. \\
\hline Salmon LYVE-1 & 272 & NISDETNTDSASE------------- \\
\hline Zebrafish Lyve-1 & 281 & EEQMEEKNQE---ELDENHQEEQMEERRQEEHMKKNQEEQVEENDSSSAEQ \\
\hline
\end{tabular}

(B) 
(a) zLYVE-1

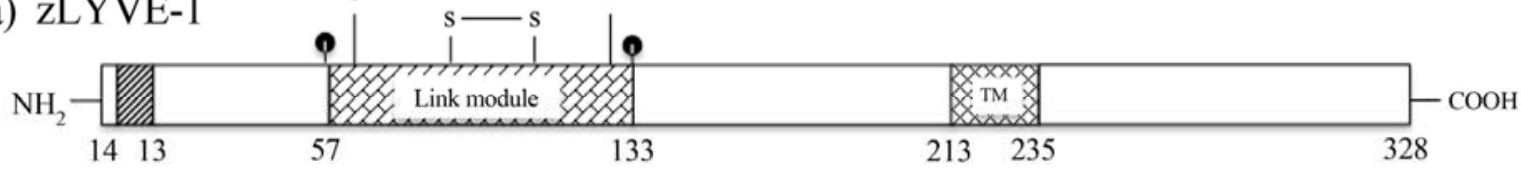

(b) sLYVE-1
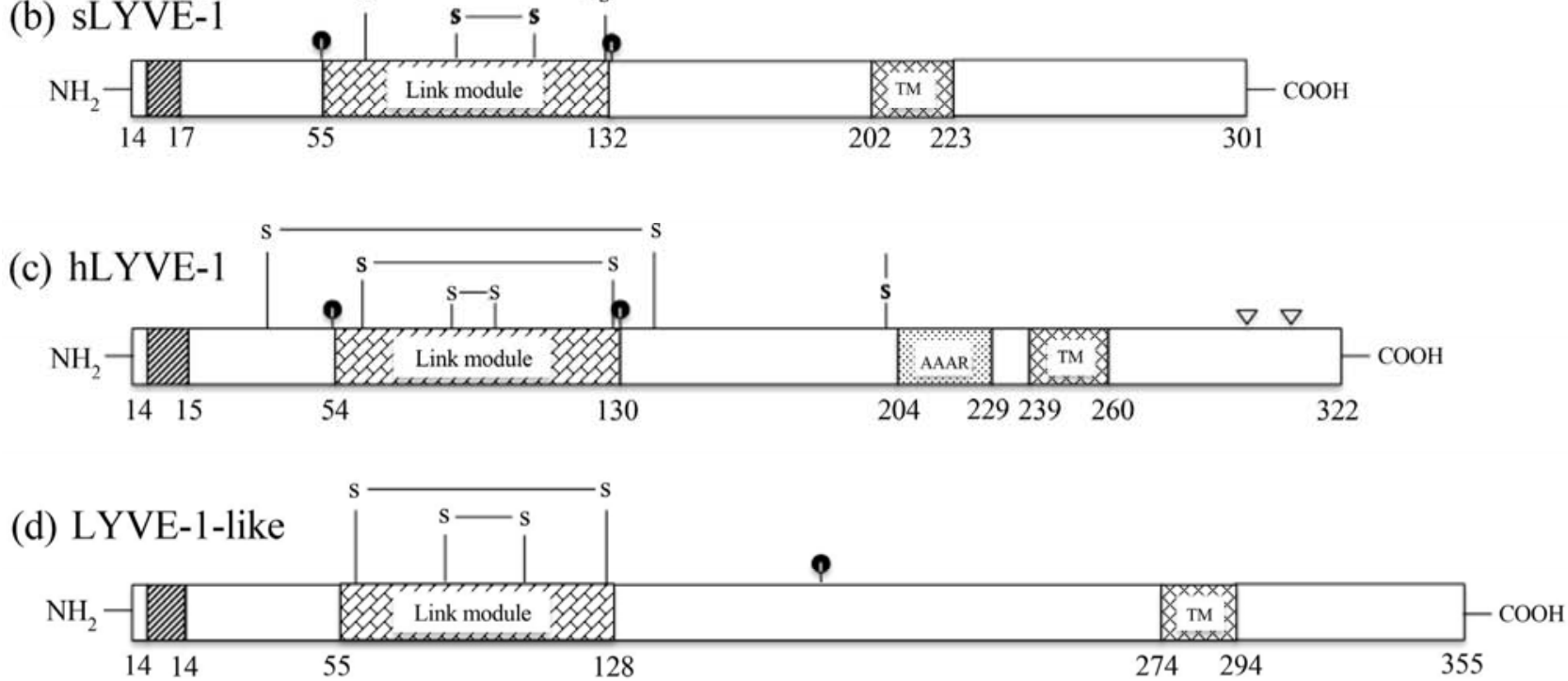

$$
\begin{array}{ll}
\text { Link module } \\
\text { Acidic amino acid-rich region (AAAR) } \\
\square \text { N-glycosylation site } \\
\square \text { Signal peptide } \\
\square-\text { Transmembrane domain (TM) } \\
s-s \text { Intramolecular disulfide bond } \\
s- & \text { Intermolecular disulfide bond } \\
\nabla & \text { Putative Phosphorylation site }
\end{array}
$$

(C)

Figure 1. zLyve-1 (or zLYVE-1) exhibits amino-acid-sequence ((A), (B)) and structural domain (C) homology with those of other vertebrate homologs. (A) The nucleotide and deduced amino-acid sequences of zlyve1 cDNA cloned from zebrafish were determined as described in the text. Two potential $N$-linked glycosylation sites are boxed. The half-cystine residues are marked by circles. The boundaries of the exons of zlyve1 cDNA are distinguished by the shaded and unshaded sequences; (B) The deduced amino acid sequence of zLyve-1 is aligned with those of other vertebrate homologs (human, chimpanzee, dog, cow, mouse, rat, horse, chicken and salmon). The arrow indicates the identified $\mathbf{N}$-terminal amino acid residues in human and cow LYVE-1 (hLYVE-1 and bLYVE-1, respectively) (3). Identical amino acid residues in zebrafish and other vertebrate homologs are marked by shaded boxes. The Link module and transmembrane domain are underlined. The AAAR domain present in other vertebrat homologs is over-lined and is absent in the zebrafish and salmon orthologs (zLyve-1 and sLYVE-1). Identical half-cystine residues in all vertebrate LYVE-1 species are indicated by $\Delta$. Half-cystine residues, which are only present in other vertebrate homologs, are indicated by $\Delta$. Two potential $\mathrm{N}$-linked glycosylation sites are marked by *. The bar indicates the absence of the corresponding amino acid residues in the zebrafish ortholog, salmon ortholog and other vertebrate homologs; (C) zLyve-1 (panel a) and sLYVE-1 (panel b) lack the AAAR domain and contain 2 versus 3 disulfide bonds compared to hLYVE-1 (panel c) or other mammalian homologs. The 2 disulfide bonds are present in the Link domain in all vertebrate LYVE-1 homologs. The third disulfide bond seen in hLYVE-1 or other vertebrate LYVE-1 homologs is localized outside the Link module. The two N-linked glycosylation sites are localized at both sides of the Link module in all vertebrate LYVE-1 homologs. In contrast, the zLyve-1-like (panel d) lacks the N-linked glycosylation sites in the Link module. 
cently identified by Flores et al. [16], does not have this important structural feature and is termed Lyve-1-like in this communication (Supplementary Figure S1 and Figure $\mathbf{1 ( C )}$, panel $d)$. The close protein structure-feature similarity of the identified zLyve-1 and other known vertebrate LYVE-1 homologs suggests that the cloned zlyve1 is the authentic ortholog of LYVE-1 in zebrafish.

In contrast to all other known vertebrate homologs (e.g., human LYVE-1), zLyve-1 and the other fish homolog, salmon LYVE-1 (sLYVE-1) do not contain an acidic-amino-acid-rich domain (AAAR) which is separated from the Link module and close to the transmembrane domain (Figures 1(B) and (C), panels a and b vs. panel c). We hypothesize that the AAAR domain orients its acidic side chains of Glu residues toward the basic side chains in the molecule-surface clustered basic amino acid residues of its cognate ligands, including PDGF-BB, VEGF-A $^{165}$, IGFBP-3 and FGF2 [1-3,7,18]. zLyve-1 and sLYVE-1 do not possess this AAAR domain and are expected to lack growth factor/cytokine (with surface clustered basic amino acid residues in the molecule) binding activity.

\subsection{Genomic Structure and Ligand Binding Activity of zLyve-1}

The zlyve 1 allele (12.2 kb) resides in chromosome 7 and consists of 6 exons and 5 introns. The genomic structure of the zlyve1 is quite similar to those of other vertebrate homologs (Supplementary Figure S2). A phylogenetic tree analysis indicates that zLyve-1-like protein (zlyve1l) is evolutionarily distantly related to all known vertebrate LYVE-1 homologs (Supplementary Figure S3). This supports the notion that zLyve-1-like protein (or zlyve1l) is not the authentic ortholog of LYVE-1 in zebrafish.

H1299 cells, which express very little endogenous LYVE-1, have been used to analyze the ligand binding activity of bovine CRSBP-1 (bCRSBP-1 or bLYVE-1) after stable transfection of these cells with its cDNA in pCEP4 vector [3]. To define the ligand (hyaluronic acid) binding activity of zLyve-1, H1299cells were transiently transfected with pCMV-zlyve1-HA and termed H1299/ zlyve1 cells. As shown in Figure 2(A), zLyve-1 expressed in H1299/zlyve1 cells was identified as a 48-kDa protein by $7.5 \%$ SDS-PAGE followed by Western blot analysis using anti-HA (hemagglutinin epitope) antibody (lane 2). The hyaluronic acid-binding activity of zLyve-1 expressed in H1299/zlyve1 cells was determined as described previously [3] by the following procedure: Triton $\mathrm{X}-100$ extracts $(100 \mu \mathrm{g}$ protein) of H1299 cells transfected with expression vector containing zlyve1 cDNA (H1299/zlyve1 cells) or with empty vector (H1299/vector cells) were incubated with several concentrations of hyaluronic acid (M.W. 2,000,000). The hyaluronicacidzLyve-1 complex in the Triton X-100 extracts was then precipitated by cetylpyridinium chloride (CPC) followed by Western blot analysis using anti-HA (hemagglutinin epitope) antibody as described [3]. The relative amounts of zLyve-1 on the blots, which represented those of zLyve-1-hyaluronic acid complexes precipitated by CPC, were estimated. As shown in Figure 2(B), hyaluronic acid formed complexes with zLyve-1 in a concentration-dependent manner with a half-maximal concentration of $30 \pm 5 \mu \mathrm{g} / \mathrm{ml}(\mathrm{n}=4)$ (panels $\mathrm{a}$ and $\mathrm{b})$. This is equivalent to the apparent $\mathrm{K}_{\mathrm{d}}(\sim 15 \mathrm{nM})$ of hyaluronic acid binding to other vertebrate LYVE-1 homologs [3]. This suggests that zLyve-1 and mammalian LYVE-1 homologs bind hyaluronic acid with the similar affinity.

To determine the growth factor binding activity of zLyve-1, we performed direct binding analysis of $\mathrm{I}^{125}$ labeled VEGF peptide ( $\mathrm{I}^{125}$-VEGF peptide) in H1299 cells transiently transfected with pCMV-zlyve1-HA (termed H1299/zlyve1 cells). VEGF peptide is a 25-mer peptide containing the cell-surface retention sequence (CRS) motif of VEGF-A ${ }^{165}[1-3,7]$. We reasoned that, if zLyve-1 possesses $I^{125}$-VEGF peptide binding activity, H1299/zlyve1 cells should exhibit more specific binding (estimated in the presence and absence of 100-fold excess of unlabeled VEGF peptide) of I $^{125}$-VEGF peptide than that found in H1299/vector cells which were H1299 cells stably transfected with vector only [3]. As shown in Figure 2(C), H1299/zlyve1 cells exhibited less specific binding of $\mathrm{I}^{125}$-VEGF peptide than that found in H1299/ vector cells, rather than more specific binding. The apparent $\mathrm{I}^{125}$-VEGF peptide specific binding found in these cells (H1299/vector and H1299/zlyve1 cells) appeared to be mediated by other membrane proteins (e.g., low-affinity binding proteins such as proteoglycans) [1]. We speculate that the lower low-affinity specific binding in H1299/zlyve1 cells may be due to lower expression of proteoglycans in these cells. In a positive control experiment, H1299/bLYVE-1 cells (which stably express bovine LYVE-1 (bLYVE-1) that is known to have growth factor binding activity) [3] exhibited more specific binding (bLYVE-1-mediated) of $\mathrm{I}^{125}$-VEGF peptide than those of H1299/vector and H1299/zlyve1 cells. This suggests that zLyve-1 may not possess $\mathrm{I}^{125}$-VEGF peptide binding activity. To further test for $\mathrm{I}^{125}$-VEGF peptide binding activity of zLyve-1, we performed $\mathrm{I}^{125}$-VEGF peptide-affinity labeling in H1299/zlyve1 cells and H1299/bLYVE-1 cells (as a positive control). This labeling technique identifies mammalian LYVE-1 (also termed CRSBP-1) in cultured cells and tissue extracts $[1-3,7]$. The cells were incubated with $\mathrm{I}^{125}$-VEGF peptide and cross-linked with 1-ethyl-3-(3-dimethylaminopropyl) carbodiimide $\mathrm{HCl}$ (EDAC) as described previously [1-3,7]. As shown in Figure 2(D), H1299/bLYVE-1cells exhibit a $\sim 60$-kDa I ${ }^{125}$-VEGF peptide-affinity-labeled bLYVE-1 and its 45-kDa proteolytic product (lane 2), 


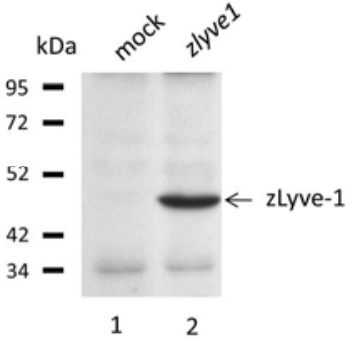

(A)

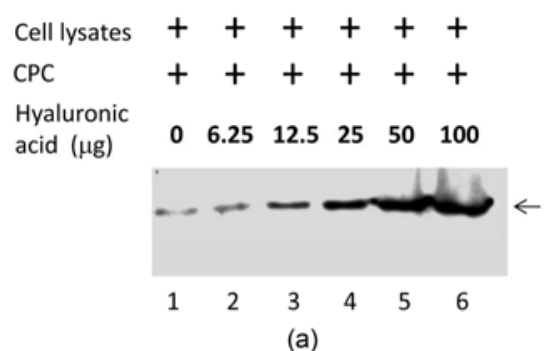

(a)

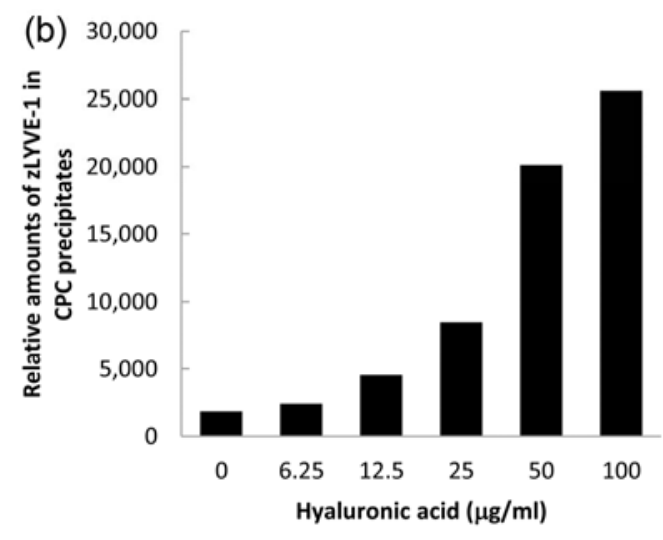

(B)

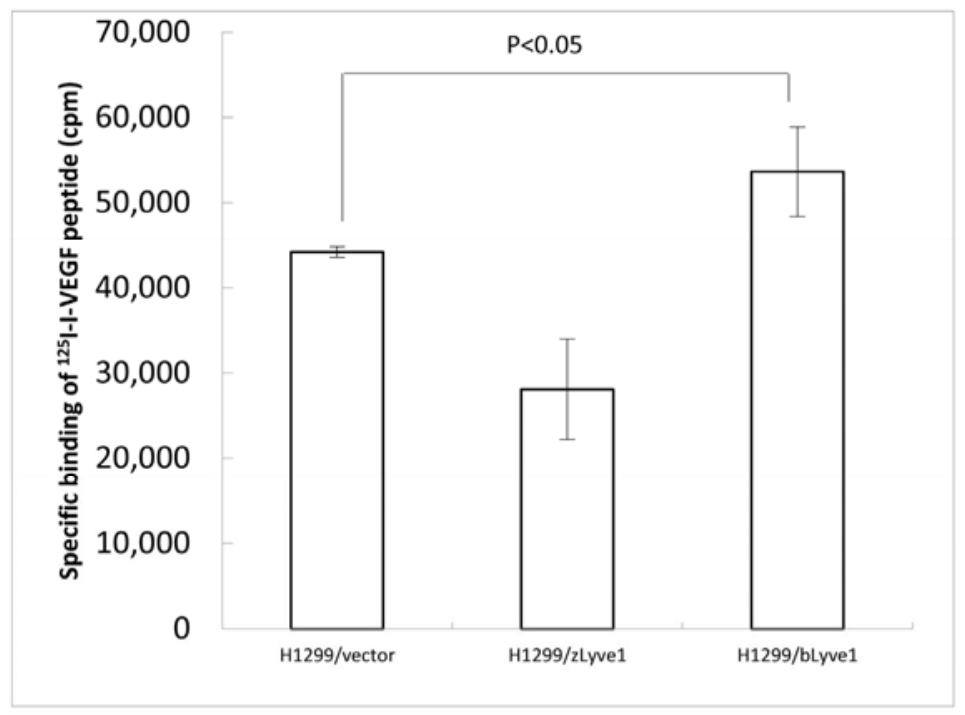

(C)

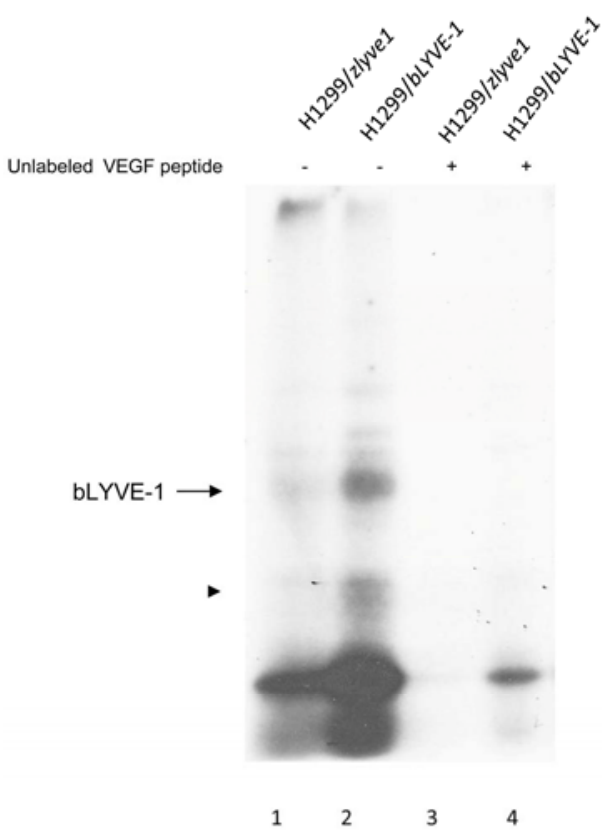

(D)

Figure 2. zLyve-1 expressed in H1299/zlyve1 cells is a 48-kDa protein (A) and exhibits hyaluronic acid binding activity (B) but lacks ${ }^{125}$ I-VEGF peptide-binding activity ((C), (D)). (A) Cell lysates of H1299/zlyve1 and H1299/vector cells were analyzed by 7.5\% SDS-PAGE followed by Western blot analysis using anti-HA antibody. A 48-kDa protein was found in the cell lysates from H1299/zlyve1 cells (lane 2) but not in those of H1299/vector cells (lane 1). This suggests that zLyve-1 is a protein with M.W. $48 \mathrm{kDa}$; (B) The hyaluronic acid binding activity of zLyve-1 was determined by incubation of the Triton X-100 extracts of H1299/zlyve1 cells with several concentrations of hyaluronic acid followed by CPC precipitation and 7.5\% SDS-PAGE/ Western blot analysis using anti-HA antibody (panel a). The arrow indicates the location of zLyve-1. The relative amounts of zLyve-1 in the CPC precipitates were quantified (panel b); (C) The ${ }^{125}$ I-VEGF peptide-binding activity of zLyve-1 was determined by direct binding analysis in H1299/vector, H1299/zlyve1 and H1299/bLYVE-1 (as a positive control) cells as described in the text. The specific binding of ${ }^{125}$ I-VEGF peptide in these cells was determined by subtracting non-specific binding (which was estimated in the presence of 100-fold excess of unlabeled VEGF peptide) from total binding. H1299/zlyve1 cells did not exhibit more specific binding (zLyve-1-mediated) of ${ }^{125}$ I-VEGF peptide when compared with that found in H1299/ vector cells. In the control experiment, H1299/bLYVE-1 cells showed more specific binding of ${ }^{125}$ I-VEGF peptide than H1299/vector cells, as previously described (3); (D) The ${ }^{125}$ I-VEGF peptide-binding activity of zLyve-1 was also determined by ${ }^{125}$ I-VEGF peptide-affinity labeling. H1299/zlyve1 and H1299/bLYVE-1 cells were incubated with ${ }^{125}$ I-VEGF peptide in the absence $(-)$ and presence $(+)$ of 100 -fold excess of unlabeled VEGF peptide (lanes 1,2 and lanes 3 , 4, respectively) at $4^{\circ} \mathrm{C}$ for 2.5 h. ${ }^{125}$ I-VEGF peptide-affinity labeling was performed using EDAC. The ${ }^{125}$ I-VEGF peptide-affinity labeled cell lysates were analyzed by $7.5 \%$ SDS-PAGE followed by autoradiography. A $\sim 60$-kDa ${ }^{125}$ I-VEGF peptide-affinity labeled protein (bLYVE-1) and its 45-kDa proteolytic product, as indicated by an arrow and arrowhead, respectively, were found in the cell lysates of H1299/bLYVE-1 cells (lane 2) as described (3, 7) but not in those of H1299/zlyve1 cells (lane 1). The ${ }^{125}$ I-VEGF peptide-affinity labeling was blocked in the presence of 100-fold excess of unlabeled VEGF peptide (lane 4). This result suggests that, although bLYVE-1 exhibits detectable ${ }^{125}$ I-VEGF peptide-binding activity, zLyve-1 does not. 
as described previously $[1-3,7]$. The $\mathrm{I}^{125}$-VEGF peptideaffinity labeling of bLYVE-1 was blocked in the presence of 100-fold excess of unlabeled VEGF peptide (lane 4). In contrast, H1299/zlyve1 cells did not show $\mathrm{I}^{125}$-VEGF peptide-affinity-labeled zLyve-1 (lane 1). The predicted molecular weight of $\mathrm{I}^{125}$-VEGF peptide-affinity-labeled zLyve-1 would be $\sim 50 \mathrm{kDa}$ if zebrafish Lyve-1 was capable of binding $\mathrm{I}^{125}$-VEGF peptide. H1299 cells expressed a very low level of endogenous LYVE-1 (lane 1). Taken together, these results suggest that zLyve-1 does not have $I^{125}$-VEGF peptide-binding activity, as bLYVE 1 does. These results are also consistent with the observation that zLyve- 1 lacks the AAAR domain which is believed to mediate binding of peptides and growth regulators containing CRS motifs [1-3,7].

\subsection{Requirement of zLyve-1 for Thoracic Duct (TD) Formation}

In zebrafish, the TD is the first perfused lymphatic organ and is located between the dorsal aorta (DA) and posterior cardinal vein (PCV). It has been reported that formation of the TD in zebrafish requires the functions of prox 1 and vegfc genes $[19,20]$. However, the important role of prox1 in TD formation is currently unclear [21]. Like prox1, mammalian LYVE-1 is primarily expressed in LECs and has been used as a specific marker for these cells. zLyve-1 may also be required for lymphatic vessel formation in zebrafish. To test this possibility, we determined the role of zLyve-1 in the development of lymphatic vessels in wild-type zebrafish by knocking down zLyve-1 levels using embryo microinjection with antisense morpholino oligonucleotides (MOs). We designed antisense MOs which targeted 5' UTR (MO1) and the boundaries between exon 1 and intron 1 (MO2) and intron 1 and exon 2 (MO3), and mis-paired MO2, mis-paired MO3 and control MO (Table 1). MO2 was the most effective of the MOs used to inhibit translation of zLyve-1 and to generate a TD defect in the embryos which received MO2 injection (Table 1). To exclude off-target effects of MO2, we also co-injected MO2 with pCMVzlyve1-HA into zebrafish embryos and examined the zLyve-1 levels and phenotypes of zebrafish embryos. Rescue of the phenotype by cDNA-based overexpression of the targeted transcript has been used to confirm the specificity of MO targeting in zebrafish [22,23]. As shown in Figure 3(A) (panel a), injection of MO2 alone at the one-cell stage greatly reduced the level of zLyve-1 in zebrafish embryos, as determined by RT-PCR which yielded a 308-base pair product. MO2 completely knocked down zLyve-1 expression at 1 and 2 dpf (lanes 2 and 4 vs. lanes 1 and 3). Low levels ( $<20 \%$ ) of zLyve- 1 were observed at 3 - 5 dpf (lanes 6, 8 and 10 vs. lanes 5, 7 and 9). It is important to note that, in zebrafish embryos
Table 1. Effect of embryo injection with and without MOs on TD formation in $T g(f l i 1: E G F P)$ zebrafish.

\begin{tabular}{ccccc}
\hline \multirow{2}{*}{ Injection $^{\text {a }}$} & \multirow{2}{*}{ Embryos (at 0 dpf) } & \multicolumn{2}{c}{ Embryos (at $\mathbf{5}$ dpf) } \\
\cline { 3 - 5 } MO1 & $4.2 \mathrm{ng}$ & 200 & $166(83 \%) \mathrm{T}$ & $0^{\mathrm{f}}$ \\
& $8.4 \mathrm{ng}$ & 200 & $158(79 \%) \mathrm{e}$ & $0^{\mathrm{f}}$ \\
MO2 & $4.2 \mathrm{ng}$ & 200 & $155(77 \%) \mathrm{e}$ & 32 \\
& $8.4 \mathrm{ng}$ & 200 & $148(74 \%) \mathrm{e}$ & 80 \\
MO3 & $4.2 \mathrm{ng}$ & 200 & $162(81 \%) \mathrm{e}$ & $0^{\mathrm{f}}$ \\
& $8.4 \mathrm{ng}$ & 200 & $154(77 \%) \mathrm{e}$ & 10 \\
Mis-paired MO2 & $8.4 \mathrm{ng}$ & 200 & $161(80 \%) \mathrm{e}$ & $0^{\mathrm{f}}$ \\
Mis-paired MO3 & $8.4 \mathrm{ng}$ & 200 & $159(79 \%) \mathrm{e}$ & $0^{\mathrm{f}}$ \\
Control MO $^{*}$ & $8.4 \mathrm{ng}$ & 200 & $168(84 \%) \mathrm{e}$ & $0^{\mathrm{f}}$ \\
Mock $^{\mathrm{c}}$ & $8.4 \mathrm{ng}$ & 200 & $165(82 \%) \mathrm{e}$ & $0^{\mathrm{f}}$ \\
No injection $^{\mathrm{d}}$ & & 200 & $170(85 \%) \mathrm{e}$ & $0^{\mathrm{f}}$ \\
\hline
\end{tabular}

at 0 dpf, $\operatorname{Tg}(f l i 1: E G F P)$ zebrafish embryos (200 per experimental group) were injected with 4.2 and 8.4 ng of M01, M02, M03, mis-paired M02 and mis-paired M03, and with mock. At $5 \mathrm{dpf}$, zebrafish were examined. ${ }^{\mathrm{b}}$ The embryos (survived at $5 \mathrm{dpf}$ ) with abnormal phenotypes (pericardial edema and bent tail) were examined for the absence of the TD under a confocal fluorescence microscope. All embryos with a TD defect (no thoracic duct) had pericardialedema. ${ }^{\mathrm{c}}$ Phenol red injection. ${ }^{\mathrm{d}}$ Embryos without injection exhibited a $85 \%$ survival rate under the experimental conditions. ${ }^{\text {eSurvival }}$ rate at 5 dpf. ${ }^{\text {f }}$ No detectable TD defect.

not injected with MO2, zLyve-1 was expressed at the highest level at $3 \mathrm{dpf}$ and gradually decreased afterward (Figure 3(A), panel a, lane 5). Co-injection with pCMVzlyve1-HA reversed MO2-injection-induced knockdown of zLyve-1 levels, as determined by RT-PCR, using a different pair of primers (forward + reverse). This yielded a 461-base pair product (Figure 3(A), panel b, lane 3 vs. lanes 1, 2). Injection with MO2 caused edema in the pericardial sac, bent tail and a decreased survival rate (Figure 3(B), panel b vs. panel a and Table 1). Under our experimental conditions, the survival rate of zebrafish at 5 dpf with control MO andd MO1 was 79\% - 84\% (Table 1). The survival rates of zebrafish injected with $8.4 \mathrm{ng}$ MO2 and $8.4 \mathrm{ng}$ MO3 were less (74\% - 77\%). The MO2-injection-induced phenotypes (e.g., edema) and decreased survival rate were reversed by co-injection with pCMVzlyve1-HA (Figure 3(B), panel c and Table 1). These results suggest that MO2-injected embryos may have defects in the formation and/or function of lymphatic vessels, including TD. In zebrafish, loss of the TD has been shown to result in the phenotype of pericardial edema [24]. These results also suggest that the phenotypes of pericardial edema and decreased survival rate in MO2-injected embryos are not due to off-target effects [14] but are specifically caused by the loss of zLyve-1 because the phenotypes can be rescued by co-injection 
(a)
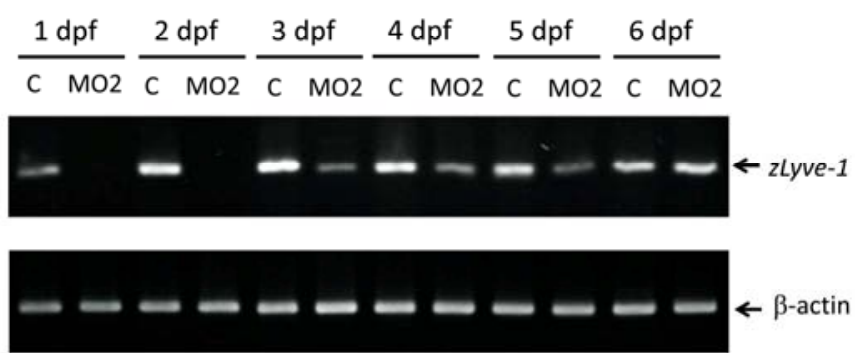

$\begin{array}{llllllllllll}1 & 2 & 3 & 4 & 5 & 6 & 7 & 8 & 9 & 10 & 11 & 12\end{array}$

(A) (b)

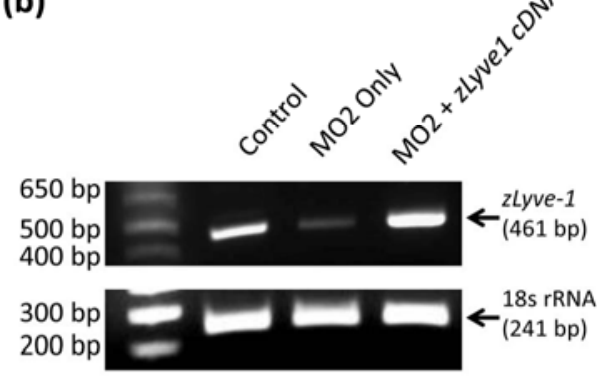

123

Control

$\mathrm{MO} 2$

$\mathrm{MO} 2$ + zlyve1 cDNA

(a)

(b)

Abnormal tail

(c)
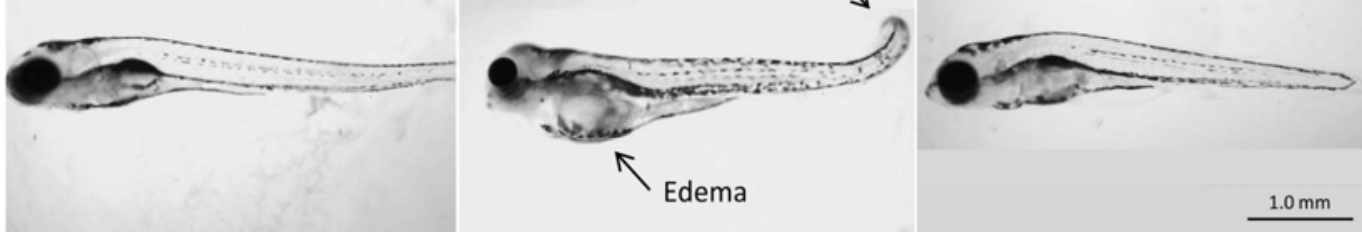

(B)

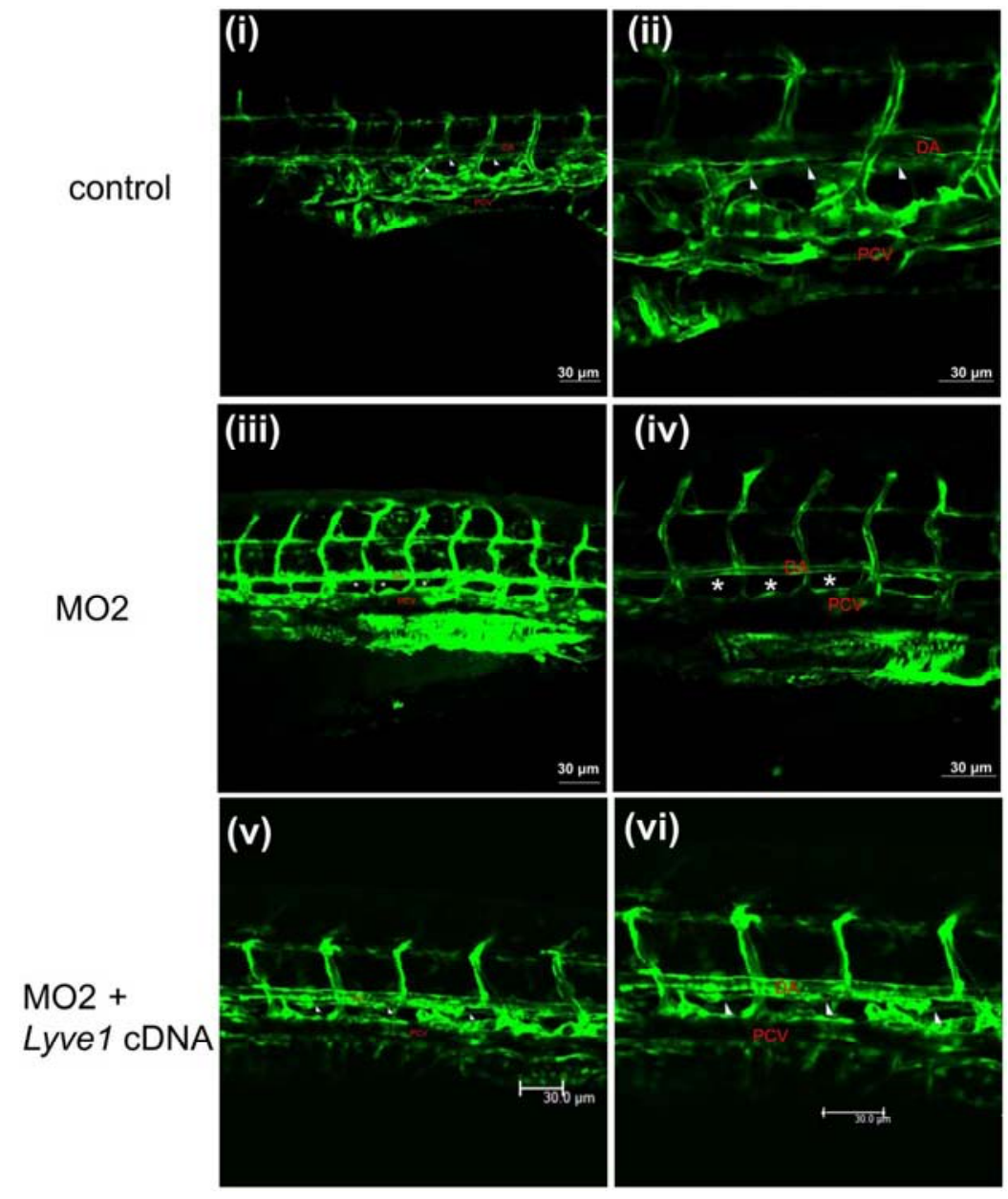

(C1) 
(a)

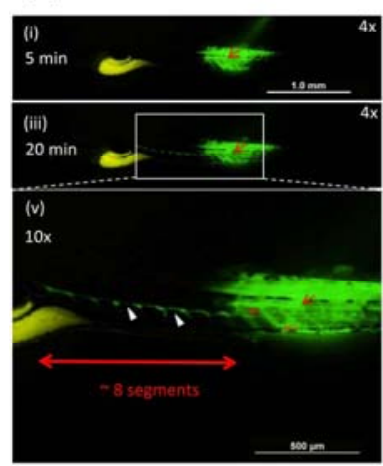

$\mathrm{MO} 2$

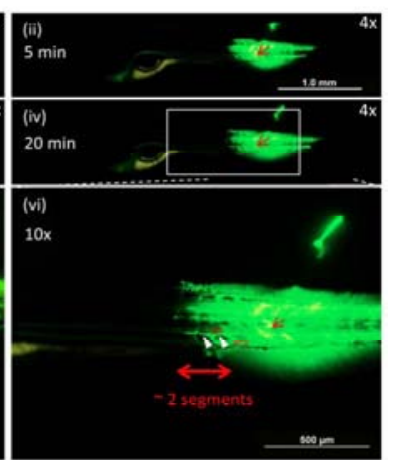

(b)

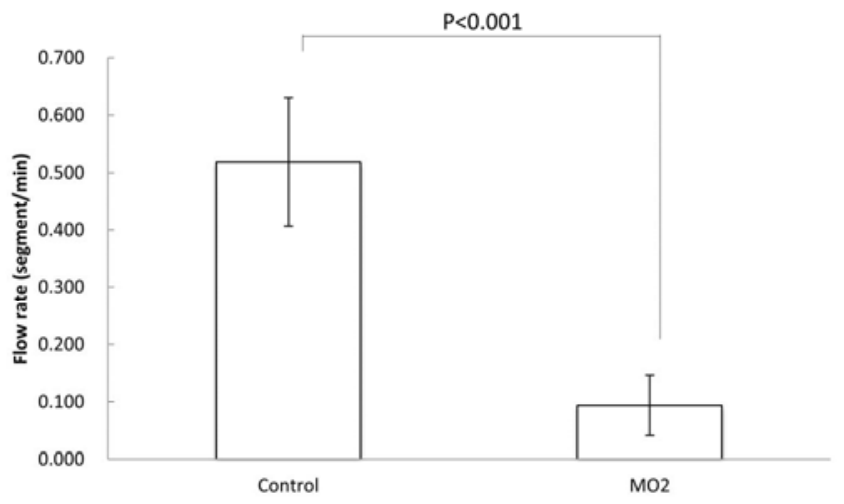

(C2)

Figure 3. Embryo microinjection with MO2 causes decreased levels of zLyve-1 (A), edema formation (B), defects of TD formation (C1), and dysfunction of TD transit of FITC-dextran (C2), that can be reversed by co-microinjection with zlyve1 cDNA, in zebrafish. (A) (panel a) The levels of zlyve1 mRNA in zebrafish embryos (at 1 - 6 dpf) injected with control MO (C, lanes 1, $3,5,7,9,11$ ) and MO2 (lanes 2, 4, 6, 8, 10, 12), were determined by measuring the level of a 308-base pair product (as indicated by the arrow) with RT-PCR analysis using the following primers: 5'-G GCCTGTTCATGTCTGGTCTG-3' (forward) and 5'-TCTGCACGCCACACCACAACC-3' (reverse). The $\beta$-actin RT-PCR product (433 base pair) was determined an internal control. The zLyve-1 mRNA levels in zebrafish embryos injected with MO2 increased at $3-5$ dpf but remained at $<20 \%$ of those seen in zebrafish derived from embryos injected with control MO (lanes 6, 8, 10 vs. lanes 5, 7, 9); (A) (panel b) The levels of zLyve-1 mRNA in zebrafish embryos injected with control MO (C, lanes 1), MO2 (lanes 2) and MO2 + zlyve1 cDNA (in pCMV-zlyve1-HA) (lane 3) were determined by measuring the level of a 461-base pair product (as indicated by an arrow) with RT-PCR analysis using the following primers: 5'-ATG ACA CGA GTC TGC ATG GG-3' (forward) and 5'-ATC GGC TTT CCG GTT GTC ATT TGG-3' (reverse). The RT-PCR product (241 base pairs) of $18 \mathrm{~s}$ rRNA in these embryos was determined as an internal control. Embryo injection with MO2 resulted in complete knockdown of zLyve-1 mRNA levels at 2 dpf (lane 2 vs. lane 1). Co-injection of MO2 with zlyve1 cDNA (in pCMV-zlyve1-HA) reversed the effect of MO2 knockdown on zLyve-1 levels in zebrafish embryos at 5 dpf (lane 3 vs. lane 2); (B) Wild-type zebrafish embryos of 5 dpf derived from MO2-injected embryos clearly exhibited tail abnormality and pericardial edema as indicated by the arrow (panel b) compared to control MO-injected zebrafish embryos (panel a). These phenotypes were reversed by co-injection with zlyve1 cDNA (in pCMV-zlyve1-HA) (panel c). Scale bar = $1 \mathrm{~mm}$; (C1) Fluorescent images (lateral view) of the trunk vasculature (head-left and tail-right orientation) from 5-dpf $T g(f l i 1: E G F P)$ zebrafish embryos derived from control MO-injected embryos (panels i and ii), MO2-injected embryos (panels iii and iv) and MO2 + zlyve1 cDNA (in pCMV-zlyve1-HA)-co-injected embryos (panels $v$ and vi) are shown. The images were taken by confocal fluorescence microscopy. Locations of DA and PCV are indicated. The TD is present (as indicated by arrowheads) in the zebrafish derived from control MO-injected embryos (panels $i$ and ii) and MO2 + zlyve1 cDNA (in pCMV-zlyve1-HA)-coinjected embryos (panels v and vi). The TD is absent between DA and PCV (as indicated by*) in the zebrafish derived from embryos injected with MO2 (panels iii and iv). No fluorescent cells (e.g., PLs) were found in the horizontal midline; (C2) FITC-dextran was injected intramuscularly into 5-dpf wild-type zebrafish embryos derived from embryos injected with control MO (panels a-i, -iii and -v) and MO2 (panels a-ii, -iv and -vi). Epifluorescent images (head-left and tail-right orientation) obtained at $5 \mathrm{~min}$ (panels a-i and -ii; $4 \times$ magnification) and 20 min (panels a-iii and -iv; 4× magnification and panels a-v and -vi; 10× magnification) after injection with FITC-dextran. The red arrow indicates the injection site; white arrowheads indicate the location of the segment in the TD. The transit speed of FITC-dextran along the segment of TD in zebrafish embryos at $5 \mathrm{dpf}$ (which were derived from embryos injected with control MO or MO2) was quantified in a time period of $20 \mathrm{~min}$ from a total of 6 independent experiments (panel b). The maximum transit distance of FITC-dextran after injection in zebrafish embryos derived from embryos injected with MO2 was $\sim 2$ segments. This appeared to be due to the defect in TD formation beyond the 2 segments toward the head. Locations of DA and PCV are indicated.

with pCMV-zlyve1-HA but not with pCMV-HA (vector) (Table 2).

To test the possibilitythat zLyve-1 is required for lymphatic vessel formation and function, we examined the TDin $T g$ (fli1:EGFP) zebrafish embryos at $5 \mathrm{dpf}$ after embryo microinjection of $\mathrm{Tg}$ (fli1:EGFP) zebrafish with control MO or MO2. The TD is the main conduit of the lymphatic system. It runs through the space between DA and PCV longitudinally, inthe trunk of fluorescent transgenic $\mathrm{Tg}$ (fli1:EGFP) zebrafish [10-12,25]. Tg (fli1:
EGFP) zebrafish, which bear a egfp transgene driven by the zebrafish fli1 promoter $\mathrm{Tg}$ (fli1:EGFP), exhibit fluorescence in both blood and lymphatic vascular structures. This is used to examine the formation of blood and lymphatic vessels during development $[11,25]$. The TD in $T g$ (fli1:EGFP) zebrafish derived from embryos microinjected with control MO was analyzed using confocal fluorescence microscopy and was found to be present and not altered (Figure 3(C1), panels i and ii). It is not different from that seen in $T g$ (fli1:EGFP) zebrafish de- 
Table 2. Embryo coinjection with MO2 and pCMV-zlyve1HA reverses MO2-induced TD defect in Tg(fli1:EGFP) zebrafish.

\begin{tabular}{cccc}
\hline \multirow{2}{*}{ Injection $^{\mathbf{a}}$} & \multirow{2}{*}{$\begin{array}{c}\text { Embryos } \\
\text { (at 0 dpf) }\end{array}$} & \multicolumn{2}{c}{ Embryo (at 5 dpf) } \\
\cline { 3 - 4 } & & Total & TD defect $^{\text {b }}$ \\
\hline MO2 + pCMV-HA (vector) & 200 & $142(71 \%)^{\mathrm{c}}$ & 84 \\
$\mathrm{MO} 2+$ pCMV-zlyve1-HA & 200 & $160(80 \%)^{\mathrm{c}}$ & 5 \\
\hline
\end{tabular}

${ }^{a}$ At 0 dpf, $T g(f l i: E G F P)$ zebrafish embryo (200 per experimental group) were injected with $8.4 \mathrm{ng}$ of $\mathrm{MO} 2 \pm 0.1 \mathrm{ng}$ of pCMV-zlyve1-HA or pCMV-HA. At $5 \mathrm{dpf}$, zebrafish were examined. ${ }^{\mathrm{b}}$ The embryos with abnormal phenotypes (pericardial edema and bent tail) were examined for the absence of the TD under a confocal fluorence microscope. All embryo with a TD defect (no TD) had pericardial edema. ${ }^{\text {c} S u r v i v a l ~ r a t e ~ a t ~} 5 \mathrm{dpf}$.

rived from embryos without injection. Injection with MO2 caused defects in TD formation but had no significant effects on the formation of the blood vascular system (e.g., DA, PCV and intersegmental blood vessels) in this animal. As shown in Figure 3(C) (panels iii and iv), in embryos injected with MO2, because of the loss of TD and absence of detectable fluorescent cells (e.g., parachordal lymphangioblasts) [12,25], the area in the horizontal midline had no fluorescence (as indicated by *). This suggests that embryos injected with MO2 do not develop the TD. We hypothesize that knockdown of zLyve-1 levels by the MO2 injection in the PCV causes the defects in secondary lymphangiogenic sprouts from PCV that give rise to precursors (parachordal lymphangioblasts) of LECs forming the TD $[11,25]$. As observed with the phenotype of pericardial edema, the TD defect phenotype in zebrafish derived from embryos injected with MO2 was reversed by embryo co-injection with pCMV-zlyve1-HA (Figure 3(C1), panels $\mathrm{v}$ and vi and Table 2). To determine the effect of MO2 injection on lymphatic function, we injected FITC-dextran intramuscularly into wild-type zebrafish derived from embryos injected with MO2 \pm pCMV-zlyve1-HA or control MO. We then monitored the 20-min transit of the FITC-dextran along the TD in the trunk from the injection site toward the head in these animals. The FITC-dextran transit time from the injection site to the visible end of the TD was approximately $20 \mathrm{~min}$. As shown in Figure 3(C2) and Supplementary Figure S4 (movie), FITC-dextran fluorescence moved along the TD segment by segment with a speed of $0.52 \pm 0.12$ segment/min (mean \pm S.D., $n$ $=6$ ) in zebrafish derived from embryos injected with a control MO (Figure 3(C2), panel a: Control i, iii, v and Supplementary Figure S4(a)). Zebrafish derived from embryos injected with MO2 exhibited minimal transit ( 2 segments) of FITC-dextran fluorescence along the TD (Figure 3(C2), panel a: ii, iv vi) with a speed of 0.1 \pm 0.05 segment $/ \mathrm{min}$ (mean \pm S.D., $\mathrm{n}=6$ ) (Figure 3(C2), panel a: MO2, ii, iv, vi and Supplementary Figure S4(b)). The $\sim 2$ segments were the maximal traveling distance (in
$>20 \mathrm{~min}$ ) of FITC-dextran fluorescence. This supports our observation that defective TD formation is caused by injection with MO2 (Figure 3(C1), panels iii and iv). To rule out the possibility of "off-target" effects of $\mathrm{MO}$, we co-injected zebrafish embryos with MO2 and pCMVzlyve1-HA or pCMV-HA (vector). The FITC-dextran transit alteration phenotype in zebrafish derived from embryos injected with MO2 was reversed by embryo co-injection with pCMV-zlyve1-HA but not with pCMVHA. The speed of FITC-dextran transit in zebrafish co-injected with MO2 and pCMV-zlyve1-HA was estimated to be $0.54 \pm 0.16$ segment $/ \min$ (mean \pm S.D., $n=6$ ) which is almost identical with that obtained from embryos injected with a control MO (Figure 3(C2), panel a: $\mathrm{i}$, iii, $\mathrm{v}$ and panel b). These results indicate that zLyve-1 is required for TD formation.

\section{4. zLyve-1 Is Highly Expressed in the Posterior Cardinal Vein (PCV)}

The finding that zLyve-1 is required for TD formation in zebrafish raises the question of why LYVE-1 is not required for lymphatic development in mammalian species. Null-mutation of LYVE-1 has been shown not to affect lymphatic development in mice [26,27], although LYVE1-null mice exhibit altered morphology and function of lymphatic capillary vessels [6,7]. In zebrafish, the TD is known to arise from parachordal lymphangioblasts, which are derived from secondary lymphangiogenic sprouts from PCV [11,25]. A simple possibility is that zLyve-1 is highly expressed in PCV endothelial cells. zLyve-1 may be required for the activation of these cells to become LEC precursors (parachordal lymphangioblasts), which form TD endothelial cells, in zebrafish lymphatic development. To test this possibility, we performed in situ hybridization of zLyve-1 (Figure 4(A)) and zLyve-1-like protein (Figure 4(B)) in zebrafish larvae at 30 hpf (hours post fertilization), $3 \mathrm{dpf}, 4 \mathrm{dpf}$ and 5 dpf. As shown in Figures 4(A) and (B), zLyve-1 and zLyve-1-like protein were expressed in the PCV in zebrafish embryosat 30 hpf (panels a, b, c, and d), $3 \mathrm{dpf}$ (panels e, f, g and h), 4 dpf (panels i, j, k and l) and 5 dpf (panels $\mathrm{m}, \mathrm{n}, \mathrm{o}$ and $\mathrm{p}$ ). At 30 hpf prior to venous sprouting (which would be $36 \mathrm{hpf}$ ) [25], zLyve-1 and zLyve-1 like protein were expressed in the PCV from the caudal to the anterior parts (panels a to d). This suggests potential involvement of zLyve-1 and zLyve-1-like protein in venous sprouting and/or subsequent events. However, at 3 dpf, zLyve- 1 was expressed at the highest level in the PCV (panels e and f). This result is consistent with that obtained from RT-PCR analysis (Figure 2(A), lane 5). In contrast, zLyve-1-like protein was expressed at the highest level in PCVat $30 \mathrm{hpf}$ or earlier than $3 \mathrm{dpf}$ (panels c and d). This indicates that the temporal expression profiles of zLyve-1 and zLyve-1-like protein in PCV are dif- 


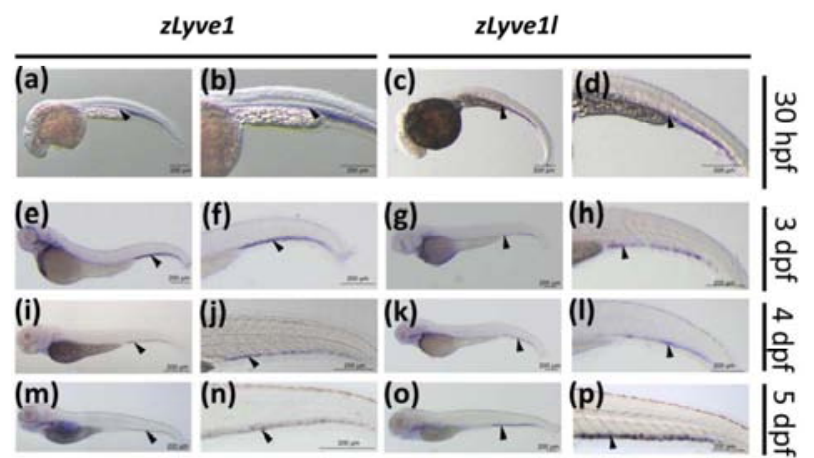

(A)

(B)

Figure 4. zLyve-1 (A) and zLyve-1-like (B) are expressed in PCV in zebrafish embryos. In situ RNA hybridization was performed on zebrafish embryos at $30 \mathrm{hpf}$ (panels a-d), 3 dpf (panels e-h), 4 dpf (panels i-l), and 5 dpf (panels m-p), using digoxigenin-labeled antisense RNA probes for zLyve1 (panels a, b, e, f, i, j, m, n) and zLyve-1-like (panels c, d, g, $h, k, l, o, p)$. Panels $a$ and $b, e$ and $f, I$ and $j, m$ and $n, c$ and $d, g$ and $h, k$ and $l$, or $o$ and $p$ represent the pictures of the same animal but with different magnifications (20 and 200 $\mu \mathrm{m}$, respectively). Hybridization was performed as described in the text. Arrowheads indicate the localization of zLyve-1 or zLyve-1-like in the PCV (panels a-p) in zebrafish embryos. The expression patterns in PCV of zLyve-1 and zLyve-1-like were similar. However, zLyve-1 was expressed at the highest level in PCV at $3 \mathrm{dpf}$ (panels e and $\mathrm{f}$ ) whereas zLyve-1-like was expressed at the highest level in PCV at 30 hpf or earlier than $3 \mathrm{dpf}$. As development progresses, the expression levels in PCV of zLyve-1 and zLyve-1-like after 3-dpf or 30 hpf decreased gradually (panels e and f, and panels $c$ and $d$, respectively). This 3 dpf time point appeared to coincide with the formation of TD, which occurred at 3.5-dpf [25].

ferent. Interestingly, at $3 \mathrm{dpf}$, the highest expression of zLyve- 1 coincides with the time point ( $3.5 \mathrm{dpf})$ seen in the formation of lymphatic vessels such as the TD, intersegmental lymphatic vessels (ISLV) and dorsal longitudinal lymphatic vessels (DLLV) in zebrafish development [25]. Both zLyve-1 and zLyve-1-like protein were specifically expressed at the vessel wall of PCV and intersegmental vessels connected to PCV (data not shown).

\section{Discussion}

Several lines of evidence indicate that zLyve- 1 is the ortholog of LYVE-1 in zebrafish. These include: 1) zLyve-1 shares important protein structural features with all other known vertebrate LYVE-1 homologs. Like all other known vertebrate LYVE-1 congeners, including mammalian and sLYVE-1, zLyve-1 is a membrane glycoprotein possessing two $\mathrm{N}$-glycosylation sites which are localized on both sides of the Link module. In contrast, zLyve-1like protein does not have such glycosylation sites on both sides of the Link module. 2) All of known vertebrate LYVE-1 orthologs contain 301 to 328 amino acid residues whereas zLyve-1-like protein is larger than these known LYVE-1 vertebrate orthologs and has 355 amino acid residues. 3) The sizes of the genes of all other known vertebrate LYVE-1 homologs, including zlyve1 and sLYVE-1 (9.4 - $18.7 \mathrm{~kb})$ are larger than zlyve1l which is small (4.2 kb). 4) A phylogenetic tree analysis indicates that zLyve-1-like protein (zlyve1l) is evolutionarily distantly related to all known vertebrate LYVE-1 homologs, including zLyve-1 and sLYVE-1.

zLyve-1 and sLYVE-1 exhibit amino acid sequence homology with other mammalian homologs but lack the acidic-amino-acid-rich (AAAR) domain which is believed to mediate its binding to growth factors/cytokines with CRS motifs $[1-3,7,18]$. This suggests that growth factor (e.g., VEGF-A, PDGF-BB and FGF2) binding activity of LYVE-1 is not important for lymphatic development in zebrafish and salmon. We demonstrate that VEGF-A and PDGF-BB from zebrafish lack the CRS motifs in their molecules (Supplementary Figures S5(a) and (b), respectively) in contrast to their mammalian counterparts. FGF2 from zebrafish also does not have a typical CRS motif in the molecule (data not shown). It appears that the LYVE-1 gene acquires the AAAR domain (which confers growth factor binding activity) at evolutionary stages beyond fish. We speculate that the development of the LYVE-1 gene with an AAAR domain in evolution may be associated with the acquisition of certain biological processes (e.g., adaptive immunity) involving growth factors and cytokines that possess CRS motifs. For example, the growth factor/cytokine-stimulated transit of immune cells from the interstitial space to lymph nodes is believed to be involved in the adaptive immune response in mammals [7,8]. LYVE-1 ligands (e.g., PDGF-BB, VEGF-A $^{165}$, CCL19) have been shown to be required for the transit of dendritic cells from the interstitial space to lymph nodes during immune responses in mammals such as mice $[7,28]$. Fish is known to have a very limited development of adaptive immunity [29]. This may be due to the lack of the AAAR domain in the LYVE-1 molecule and the CRS motifs in these growth factors/cytokines (PDGF-BB and VEGF-A) in fish.

In this communication, we demonstrate that embryo MO2 knockdown of zLyve-1 results in disruption of TD formation and impaired TD flow in zebrafish. Because zLyve-1-like protein-knock down zebrafish are phenotypically normal (16, data not shown), it appears that zLyve-1, but not zLyve-1-like protein, expressed in PCV plays an important role in the formation of the TD. zLyve-1-like protein does not appear to compensate for the loss of zLyve-1 in TD formation in zebrafish injected with MO2. The exact role of zLyve-1 in the secondary lymphangiogenic sprouts from PCV (that give rise to precursors of LECs forming the TD) [11] is unknown. We hypothesize that zLyve-1 may mediate signaling which 
leads to cellular activation of PCV endothelial cells to become LEC precursors (parachordal lymphangioblasts) after interaction with hyaluronic acid or unknown ligands. This hypothesis is based on our recent finding that mammalian LYVE-1 mediates signaling via its partner PDGF $\beta$-type receptor after interaction with its ligands, including hyaluronic acid [7].

\section{Acknowledgements}

We thank Frank E. Johnson, M.D. for critically reviewing the manuscript and Rachael Sheridan for zebrafish husbandry. This work was supported by NIH grants NS 060074 to MMV, AR052578 to SSH and AA 019223 to JSH.

\section{REFERENCES}

[1] C. Boensch, M. D. Kuo, D. T. Connolly, S. S. Huang and J. S. Huang, "Identification, Purificationand Characterization of Cell-Surface Retention Sequence-Binding Proteins from Human SK-Hep Cells and Bovine Liver Plasma Membranes,” Journal of Biological Chemistry, Vol. 270, No. 4, 1995, pp. 1807-1816. http://dx.doi.org/10.1074/jbc.270.4.1807

[2] C. Boensch, S. S. Huang, D. T. Connolly and J. S. Huang, "Cell Surface Retention Sequence Binding Protein-1 Interacts with the V-Sis Gene Product and Platelet-Derived Growth Factor Beta-Type Receptor in Simian Sarcoma Virus-Transformed Cells,” Journal of Biological Chemistry, Vol. 274, 1999, pp. 10582-10589. http://dx.doi.org/10.1074/jbc.274.15.10582

[3] S. S. Huang, F.-M. Tan, Y.-H. Huang, S.-C. Hsu, S.-T. Chen and J. S. Huang, "Cloning, Expression, Characterization, and Role in Autocrine Cell Growth of Cell Surface Retention Sequence Binding Protein-1,” Journal of Biological Chemistry, Vol. 278, No. 44, 2003, pp. 4385543869. http://dx.doi.org/10.1074/jbc.M306411200

[4] S. Banerji, J. Ni, S. X. Wang, S. Clasper, J. Su, R. Tammi, M. Jones and D. G. Jackson, "LYVE-1, a New Homologue of the CD44 Glycoprotein, Is a Lymph-Specific Receptor for Hyaluronan,” Journal of Cell Biology, Vol. 144, No. 4, 1999, pp. 789-801.

http://dx.doi.org/10.1083/jcb.144.4.789

[5] R. Prevo, S. Banerji, D. J. Ferguson, S. Clasper and D. G. Jackson, "Mouse LYVE-1 Is an Endocytic Receptor for Hyaluronan in Lymphatic Endothelium,” Journal of Biological Chemistry, Vol. 276, No. 37, 2001, pp. 1942019430. http://dx.doi.org/10.1074/jbc.M011004200

[6] S. S. Huang, I.-H. Liu, T. Smith, M. R. Shah, F. E. Johnson and J. S. Huang, "CRSBP-1/LYVE-1-Null Mice Exhibited Identifiable Morphological and Functional Alterations of Lymphatic Capillary Vessels,” FEBS Letters, Vol. 580, No. 26, 2006, pp. 6259-6268. http://dx.doi.org/10.1016/j.febslet.2006.10.028

[7] W.-H. Hou, I.-H. Liu, C. C. Tsai, F. E. Johnson, S. S. Huang and J. S. Huang, "CRSBP-1/LYVE-1 Ligands Induce Disruption of Lymphatic Intercellular Adhesion by
Inducing Tyrosinephosphorylation and Internalization of VE-Cadherin,” Journal of Cell Science, Vol. 124, 2011, pp. 1231-1244. http://dx.doi.org/10.1242/jcs.078154

[8] W.-H. Hou, I.-H. Liu, S. S. Huang and J. S. Huang, "CRSBP-1/LYVE-1 Ligands Stimulate Contraction of the CRSBP-1-Associated ER Network in Lymphatic Endothelial Cells,” FEBS Letters, Vol. 586, No. 10, 2012, pp. 1480- 487.

http://dx.doi.org/10.1016/j.febslet.2012.04.001

[9] A. M. Kuchler, E. Gjini, J. Peterson-Maduro, B. Cancilla, H. Wolburg and S. Schulte-Merker, "Development of the Zebrafish Lymphatic System Requires VEGF-C Signaling,” Current Biology, Vol. 16, No. 12, 2006, pp. 12441248. http://dx.doi.org/10.1016/j.cub.2006.05.026

[10] K. Yaniv, S. Isogai, D. Castranova, L. Dye, J. Hitomi and B. M. Weinstein, "Live Imaging of Lymphatic Development in the Zebrafish,” Nature Medicine, Vol. 12, No. 6, 2006, pp. 711-716. http://dx.doi.org/10.1038/nm1427

[11] B. M. Hogan, L. Frank, F. L. Bos, J. Bussman, M. Witte, N. C. Chi, H. J. Duckers and S. Schulte-Merker, "Ccbe1 Is Required for Embryonic Lymphangiogenesis and Venous Sprouting,” Nature Genetics, Vol. 41, No. 4, 2009, pp. 396-398. http://dx.doi.org/10.1038/ng.321

[12] B. M. Hogan, R. Herpers, M. Witte, H. Heloterä, K. Alitalo, H. J. Duckers and S. Schulte-Merker, "Vegfc/Flt4 Signalling Is Suppressed by Dll4 in Developing Zebrafish Intersegmental Arteries,” Development, Vol. 136, No. 4, 2009, pp. 4001-4009.

[13] J. S. Eisen and J. C. Smith, "Controlling Morpholino Experiments: Don't Stop Making Antisense,” Development, Vol. 135, No. 10, 2001, pp. 1735-1743. http://dx.doi.org/10.1242/dev.001115

[14] S. Isogai, J. Hitomi, K. Yaniv and B. M. Weinstein, “Zebrafish as a New Animal Model to Study Lymphangiogenesis,” Anatomical Science International, Vol. 84, No. 3, 2009, pp. 102-111. http://dx.doi.org/10.1007/s12565-009-0024-3

[15] M. C. McKinney and B. M. Weinstein, "Chapter 4. Using the Zebrafish to Study Vessel Formation," Methods in Enzymology, Vol. 444, 2008, pp. 65-97. http://dx.doi.org/10.1016/S0076-6879(08)02804-8

[16] M. V. Flores, C. J. Hall, K. E. Crosier and P. S. Crosier, "Visualization of Embryonic Lymphangiogenesis Advances the Use of the Zebrafish Model for Research in Cancer and Lymphatic Pathologies,” Developmental Dynamics, Vol. 239, No. 7, 2010, pp. 2128-2135. http://dx.doi.org/10.1002/dvdy.22328

[17] A. J. Day and G. D. Prestwich, "Hyaluronan-Binding Proteins: Tying Up the Giant," Journal of Biological Chemistry, Vol. 277, No. 7, 2002, pp. 4585-4588. http://dx.doi.org/10.1074/jbc.R100036200

[18] N. Platonova, G. Miquel, B. Regenfuss, S. Taouji, C. Cursiefen, E. Chevet and A. Bikfalvi, "Evidence for the Interaction of Fibroblast Growth Factor-2 with the Lymphaticendothelial Cell Marker LYVE-1,” Blood, Vol. 121, No. 7, 2013, pp. 1229-1237. http://dx.doi.org/10.1182/blood-2012-08-450502

[19] L. Del Giacco, A. Pistocchi and A. Ghilardi, "Prox1b Activity Is Essential in Zebrafish Lymphangiogenesis," 
PLoS One, Vol. 5, No. 10, 2010, p. e13170. http://dx.doi.org/10.1371/journal.pone.0013170

[20] A. M. Küchler, E. Gjini, J. Peterson-Maduro, B. Cancilla, H. Wolburg and S. Schulte-Merker, "Development of the Zebrafish Lymphatic System Requires VEGFC Signaling," Current Biology, Vol. 16, No. 12, 2006, pp. 12441248. http://dx.doi.org/10.1016/j.cub.2006.05.026

[21] S. Tao, M. Witte, R. J. Bryson-Richardson, P. D. Currie, B. M. Hogan and S. Schulte-Merker, "Zebrafish Prox1b Mutants Develop a Lymphatic Vasculature, and Prox1b Does Not Specifically Mark Lymphatic Endothelial Cells,” PLoS One, Vol. 6, No. 12, 2011, p. e28934. http://dx.doi.org/10.1371/journal.pone.0028934

[22] C. E. Eckfeldt, E. M. Mendenhall, C. M. Flynn, T. F. Wang, M. A. Pickart, S. M. Grindle, S. C. Ekker and C. M. Verfaillie, "Functional Analysis of Human Hematopoietic Stem Cell Gene Expression Using Zebrafish," PLoS Biology, Vol. 3, No. 8, 2005, p. e254. http://dx.doi.org/10.1371/journal.pbio.0030254

[23] D. Sheng, D. Qu, K. H. Kwok, S. S. Ng, A. Y. Lim, S. S. Aw, C. W. Lee, W. K. Sung, E. K. Tan, T. Lufkin, S. Jesuthasan, M. Sinnakaruppan and J. Liu, "Deletion of the WD40 Domain of LRRK2 in Zebrafish Causes Parkinsonism-Like Loss of Neurons and Locomotive Defect," PLoS Genetics, Vol. 6, No. 4, 2010, p. e1000914. http://dx.doi.org/10.1371/journal.pgen.1000914

[24] S.-J. Lee, T.-H. Chan, T.-C. Chen, B.-K. Liao, P.-P. Hwang and H. Lee, "LPA1 Is Essential for Lymphatic Vessel Development in Zebrafish,” FASEB Journal, Vol. 22, No. 19, 2008, pp. 3706-3715. http://dx.doi.org/10.1096/fj.08-106088

[25] J. Bussmann, F. L. Bos, A. Urasaki, K. Kawakami, H. J. Duckers and S. Schulte-Merker, “Arteries Provide Essential Guidance Cues for Lymphatic Endothelial Cells in the Zebrafish Trunk,” Development, Vol. 137, No. 16, 2010, pp. 2653-2657. http://dx.doi.org/10.1242/dev.048207

[26] N. W. Gale, R. Prevo, J. Espinosa, D. J. Ferguson, M. G. Dominguez, G. D. Yancopoulos, G. Thurston and D. G. Jackson, "Normal Lymphatic Development and Function in Mice Deficient for the Lymphatic Hyaluronan Receptor LYVE-1,” Molecular and Cellular Biology, Vol. 27, No. 2, 2007, pp. 595-604. http://dx.doi.org/10.1128/MCB.01503-06

[27] M. X. Luong, J. Tam, Q. Lin, J. Hagendoorn, K. J. Moore, T. P. Padera, B. Seed, D. Fukumura, R. Kucherlapati and R. K. Jain, "Lack of Lymphatic Vessel Phenotype in LYVE-1/CD44 Double Knockout Mice,” Journal of Cellular Physiology, Vol. 219, No. 2, 2009, pp. 430-437. http://dx.doi.org/10.1002/jcp.21686

[28] D. F. Robbiani, R. A. Finch, D. Jager, W. A. Muller, A. C. Sartorelli and G. J. Randolph, "The Leukotriene C(4) Transporter MRP1 Regulates CCL19 (MIP-3 $\beta$, ELC)Dependent Ilization of Dendritic Cells to Lymph Nodes,” Cell, Vol. 103, No. 5, 2000, pp. 757-768. http://dx.doi.org/10.1016/S0092-8674(00)00179-3

[29] L. Tort, J. C. Balasch and S. Mackenzie, "Fish Immune System. A Crossroads between Innate and Adaptive Responses,” Inmunologia, Vol. 22, No. 3, 2003, pp. 277286. 


\section{Supplementary}

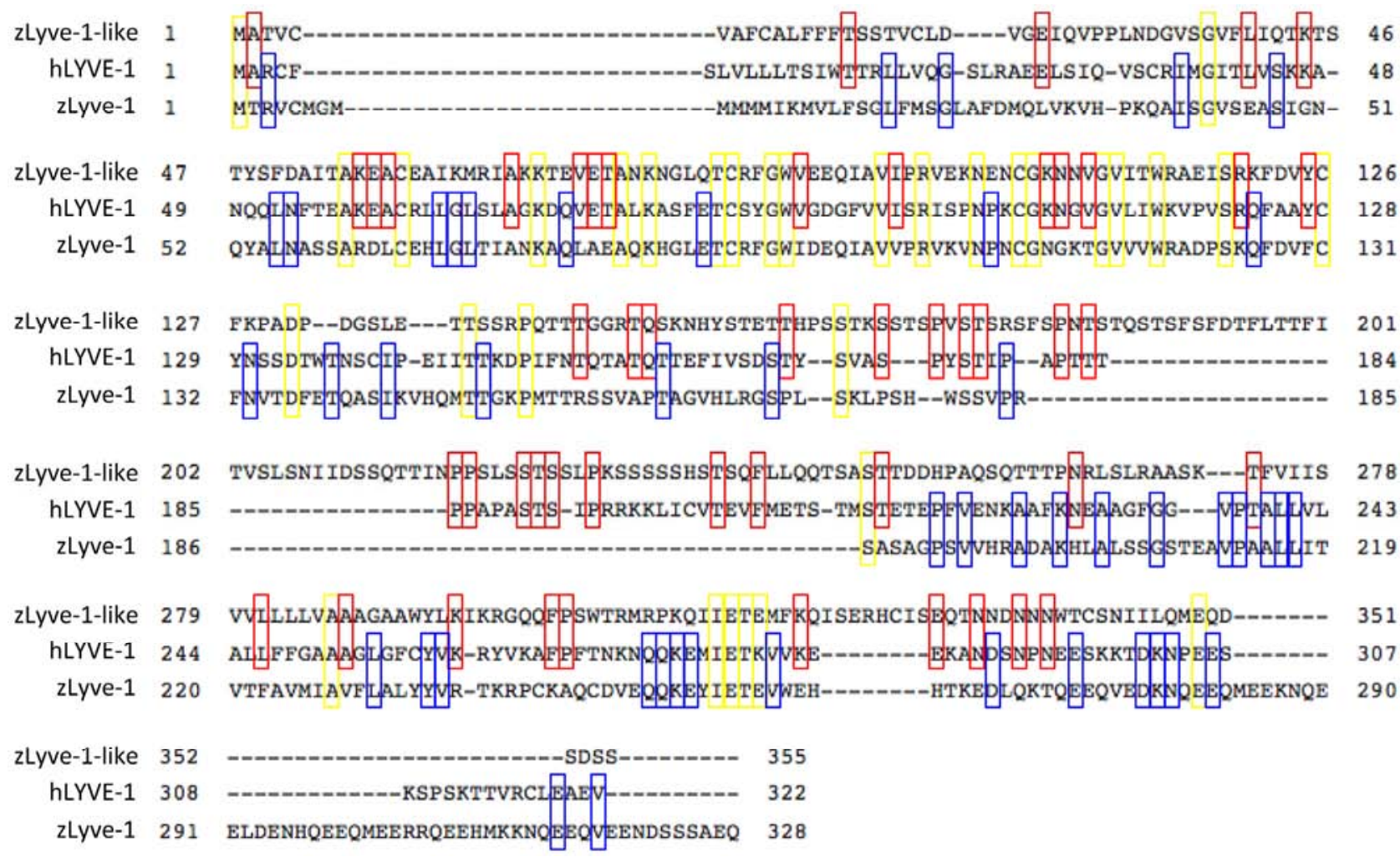

Figure S1. Comparison of the deduced amino acid sequence of zLyve-l with those of zLyve-1-like and human LYVE-1 (hLYVE-1). The deduced amino acid sequences of zLyve-1-like, zLyve-1 and hLYVE-1 are compared. Identical amino acid residues are boxed.

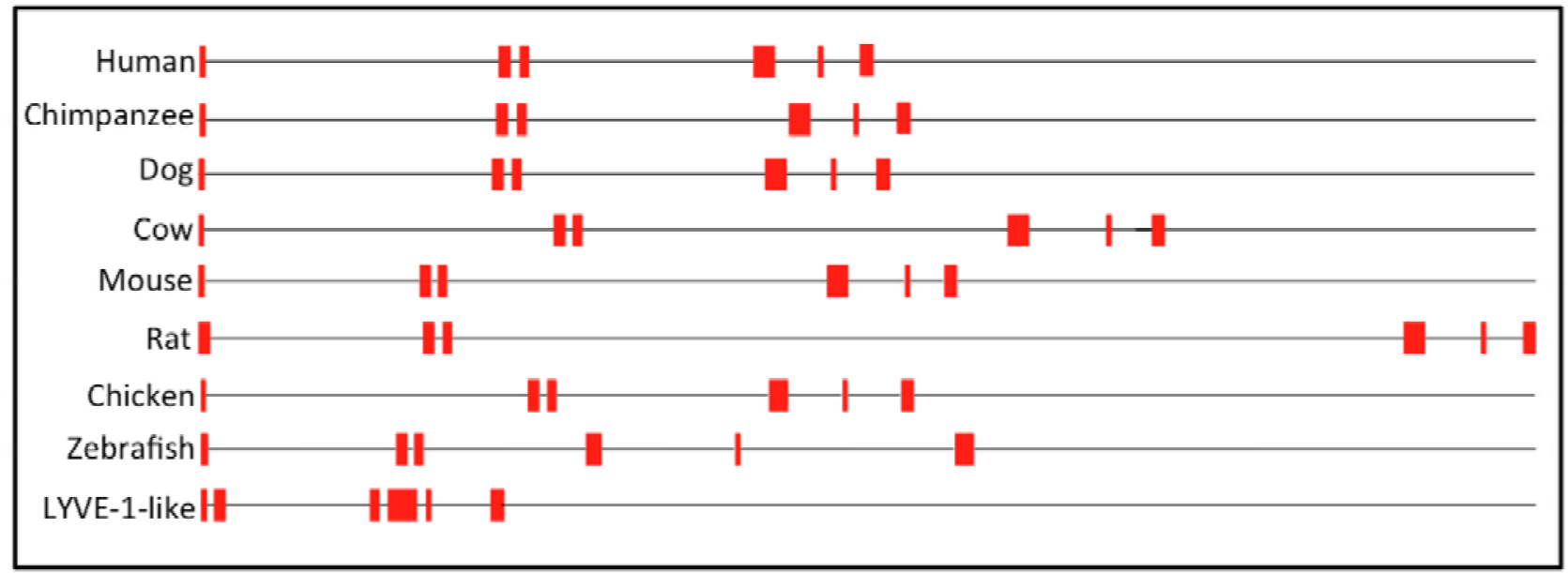

\section{Exon}

\section{Intron}

Figure S2. Genomic structure of zlyve1, but not zlyve1l, is closely similar to those of other vertebrate homologs. Genomic structure analysis was performed using the NCBI sequence viewer for the 9 compared species of the LYVE-1 family (zebrafish, salmon, chicken, rat, mouse, cow, dog, chimpanzee and human) and zlyve1l. All these vertebrate zlyve1 homologs and zlyve1l possess 6 exons and 5 introns. However, the sizes of the LYVE-1 family genes are 9.4 - $18.7 \mathrm{~kb}$ (human: $9.4 \mathrm{~kb}$; chimpanzee: $9.9 \mathrm{~kb}$; dog: $9.6 \mathrm{~kb}$; mouse: $10.6 \mathrm{~kb}$; rat: $18.7 \mathrm{~kb}$; chicken: $10.0 \mathrm{~kb}$; zebrafish: $10.8 \mathrm{~kb}$ ) whereas the size of the zlyve1l gene is $4.2 \mathrm{~kb}$. The length of introns 1,3 and 4 in the zlyve1l gene are shorter than those of the LYVE-1 family homologs. 


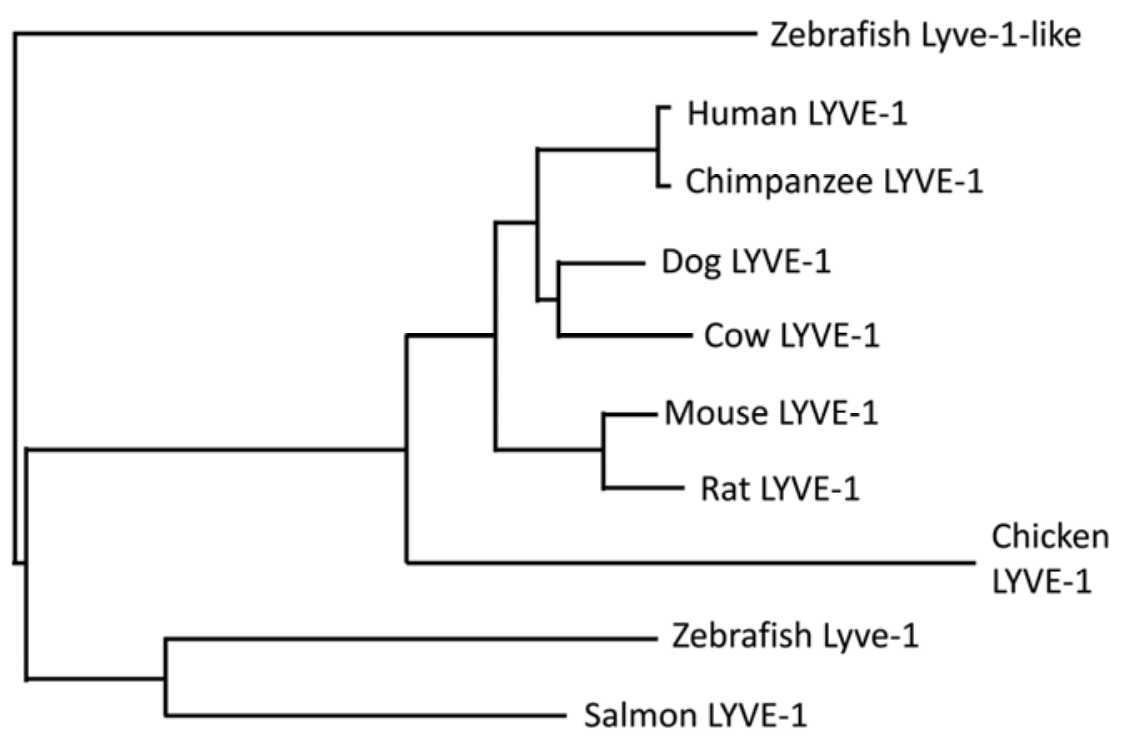

Figure S3. The zlyve1 gene is evolutionarily related to other vertebrate LYVE-1 homologs. Phylogenetic analysis was performed using the NCBI multiple alignment program. The horizontal branch lengths are proportional to the estimated time from divergence of the gene from the related homologs. 


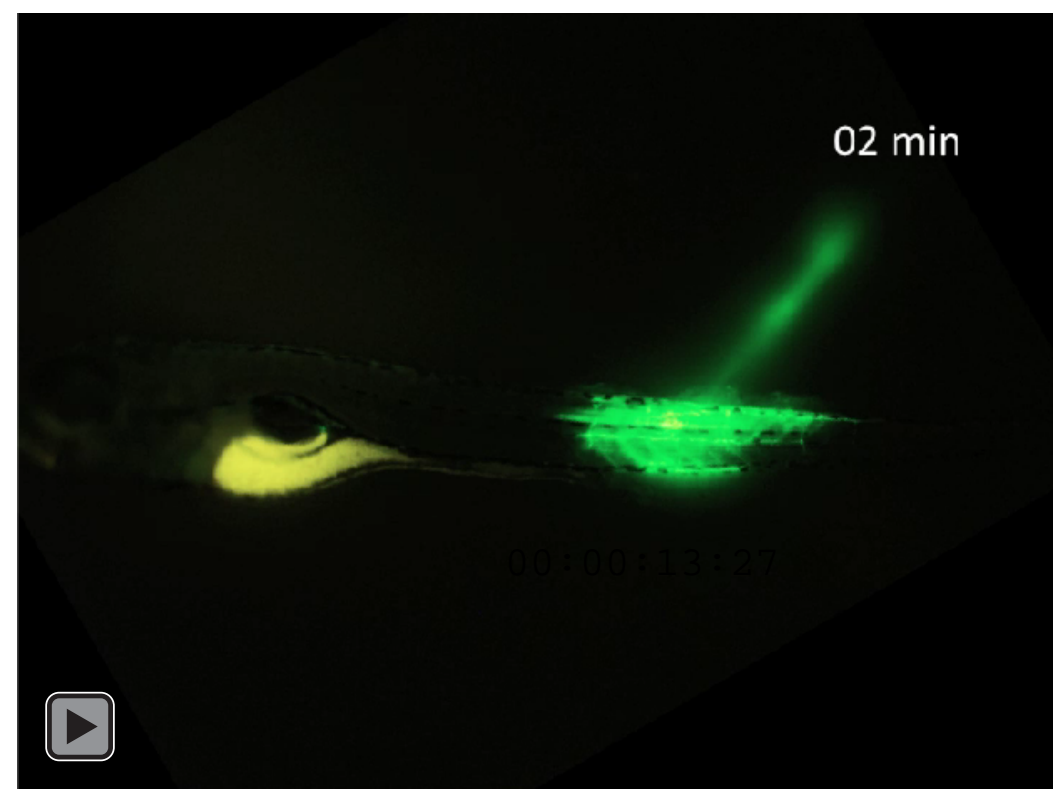

(a)

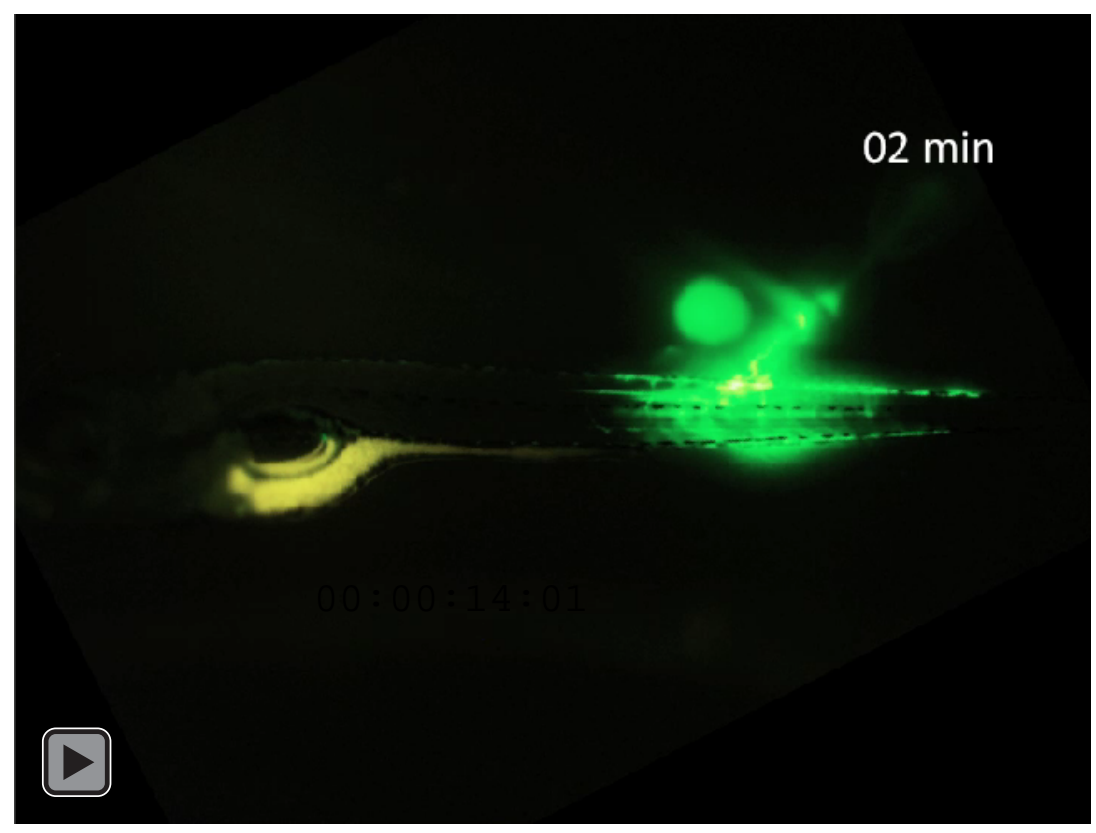

(b)

Figure S4. (movie) Movement of intramuscularly injected FITC-dextran along the TD in wild-type zebrafish derived from embryos injected with control MO (a) or MO2 (b). FITC-dextran was injected intramuscularly into 5-dpf wild-type zebrafish derived from embryos injected with control MO (a) or MO2 (b). The progression of FITC-dextran fluorescence movement along the TD (segment by segment) in the trunk was monitored by taking pictures from 5 to 20 min after FITC-dextran injection. 


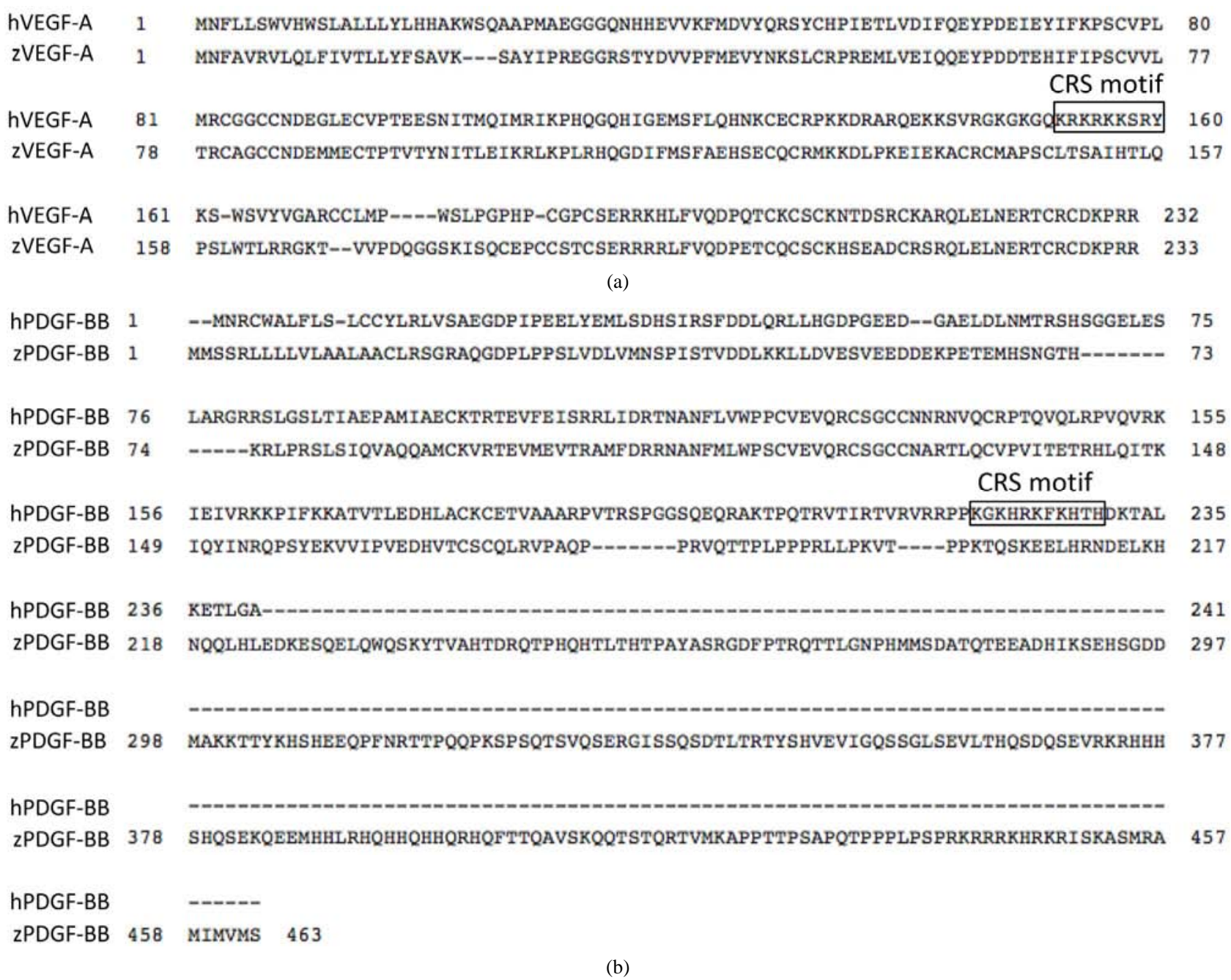

Figure S5. Comparison of deduced amino acid sequences of zebrafish VEGF-A (a) and PDGF-BB (b) with those of their human counterparts. The CRS motifs in the deduced amino acid sequences of human VEGF-A and PDGF-BB are boxed. 